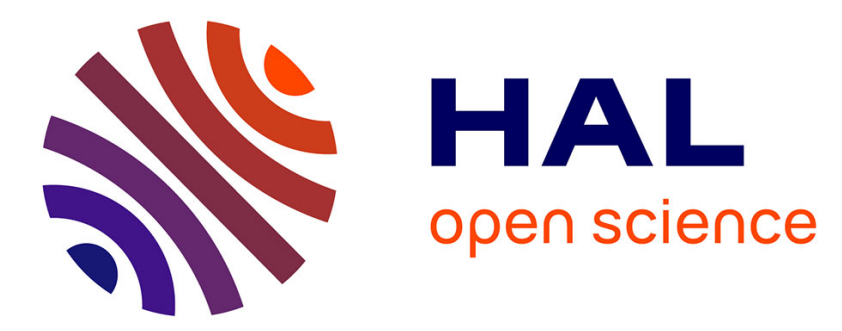

\title{
Double Negation in a Negative Concord language: An experimental investigation
}

\author{
Viviane Déprez, Susagna Tubau, Anne Cheylus, M. Teresa Espinal
}

\section{To cite this version:}

Viviane Déprez, Susagna Tubau, Anne Cheylus, M. Teresa Espinal. Double Negation in a Negative Concord language: An experimental investigation. Lingua, 2015, 163, pp.75-107. 10.1016/j.lingua.2015.05.012 . hal-01158576

\section{HAL Id: hal-01158576 https://hal.science/hal-01158576}

Submitted on 1 Jun 2015

HAL is a multi-disciplinary open access archive for the deposit and dissemination of scientific research documents, whether they are published or not. The documents may come from teaching and research institutions in France or abroad, or from public or private research centers.
L'archive ouverte pluridisciplinaire HAL, est destinée au dépôt et à la diffusion de documents scientifiques de niveau recherche, publiés ou non, émanant des établissements d'enseignement et de recherche français ou étrangers, des laboratoires publics ou privés.

\section{다(1)(2)}

Distributed under a Creative Commons Attribution - ShareAlike| 4.0 International 
1 Double Negation in a Negative Concord Language: An Experimental Investigation

3 ACCEPTED FOR PUBLICATION IN Lingua.

\section{Abstract} This paper investigates the interpretation and processing of simple transitive Catalan sentences with multiple negative expressions experimentally. Our results provide empirical confirmation that Negative Concord (NC) is the preferred and faster

9 interpretation for negative sentences that either omit or contain the overt negative marker

10 no 'not'. However, they also reveal that, in contrast to traditional descriptions of Catalan

11 and independently of particular favoring contexts, a non-negligible amount of Double

12 Negation (DN) readings arises, mainly when the negative marker co-occurs with pre-

13 verbal Negative Concord Items (NCIs), and when these NCIs have a complex DP

14 structure. Our results further suggest that two populations could be distinguished: one for

15 whom the negative marker is optional and leaves the favored NC reading essentially

16 unaffected, and another where the co-presence of no significantly increases DN readings.

17 We account for these findings within a micro-parametric approach that features

18 ambiguous NCIs (non-negative vs. negative) and a possible ambiguous negative marker

19 no (negative vs. expletive) variably available for Catalan speakers. The nuanced

- This work was presented at the Going Romance 2014: Twenty-Eighth Symposium on Romance Linguistics (Lisbon, 2014), at the Workshop on Negation: Theoretical and Empirical Investigations (Barcelona, 2014), at the $45^{\text {th }}$ Linguistic Symposium on Romance Languages (Campinas, 2015), and at the Laboratoire de Linguistique Formelle-Paris7 (Paris, 2015). We are grateful to the audiences of these conferences and seminar, and to two anonymous reviewers for all their comments and suggestions on an earlier version of the paper. We acknowledge our gratitude to the students and colleagues at the Universitat Autònoma de Barcelona who participated in the experiments as Catalan subjects. This research has been funded by the following research grant awarded by the Spanish Ministerio de Ciencia e Innovación (FFI2011-23356, FFI2014-52015-P), and by a grant awarded by the Generalitat de Catalunya to the Centre de Linguística Teòrica (2014SGR-1013). The last author also acknowledges an ICREA Acadèmia award. 
empirical NC landscape that our experimental work reveals serves to stress the

21 importance of taking DN readings into consideration for a better understanding of the

22 nature of negative constructions in Catalan and cross-linguistically.

24 Keywords: Negative Concord, Double Negation, experimental approach, micro25 parametric account, ambiguous Negative Concord Items, Catalan

\section{Introduction}

28 Within the charted landscape of Negative Concord (NC) languages, Catalan is often cast

29 as a misfit because it presents the peculiarity of optionally allowing the co-presence of a

30 sentential negative marker no 'not' with pre-verbal Negative Concord Items (NCIs) ${ }^{1}$

31 (Fabra 1912, 1918, 1956; Badia i Margarit 1962, 1994; Solà 1973; Quer 1993; Vallduví

32 1994; Espinal 2000a, 2002). The central goal of the present paper is to report the results

33 of an experimental research that sought to test when, and to what extent, native speakers

34 of Catalan prefer to interpret negative sentences of various types with a single negation

35 interpretation as a Negative Concord (NC) reading, and whether, in some circumstances,

36 with specific syntactic combinations of Negative Concord Items (NCIs), with and without

37 a sentential negative marker, a Double Negation (DN) reading could emerge in simple

38 transitive clauses as it has been claimed to emerge in other NC languages like Romanian.

39 We report on two experiments that aimed at investigating the following four

40 questions. First, we tested whether it is correct, as standardly assumed by Catalan

\footnotetext{
${ }^{1}$ In this paper we opt to use the descriptive term Negative Concord Item (NCI) (Watanabe 2004) instead of the more frequently used term $n$-word (Laka 1990) to refer to expressions that can participate in Negative Concord constructions, sharing the semantic property of being licensed both in negative and in nonnegative contexts and of appearing sometimes negative by themselves. This choice seeks to steer away from the cultural connotations that the term $n$-word has taken on in the language of North-Americans.
} 
41 grammarians, that $\mathrm{NC}$ is systematically and consistently the default interpretation for 42 sequences of multiple negative terms; second, we asked whether the processing of 43 negative sequences in Catalan could be overall faster, and hence presumably easier to 44 parse, under a $\mathrm{NC}$ reading than under a $\mathrm{DN}$ one. The latter is commonly assumed to be 45 cross-linguistically marked (Corblin et al. 2006, de Swart 2010, Puskás 2012), but has 46 recently been shown, in equivalent experimental settings, to be sometimes equally fast, 47 and even sometimes faster in distinct languages; third we verified whether the co48 presence of the sentential negative marker no with pre-verbal NCIs could influence the 49 readings of negative sequences and increase DN readings and fourth, we investigated

50 whether the morpho-syntactic nature of the NCIs involved in a negative sequence could

51 influence the readings preferred by native speakers, increasing or decreasing a putative 52 preference for a $\mathrm{NC}$ vs. DN reading.

53 Regarding the first question, we aimed at investigating to what extent the default 54 nature of NC readings in Catalan can be confirmed, and whether Catalan sequences of 55 NCIs in simple transitive clauses are essentially always unambiguous, radically favouring 56 NC readings in neutral discourse and prosodic contexts across native speakers, as 57 expected from the literature. ${ }^{2}$

58 Regarding the second question, we aimed to experimentally test whether speakers 59 process $\mathrm{NC}$ readings more easily and faster than DN readings, and whether the common 60 belief that $\mathrm{DN}$ readings have a higher degree of parsing complexity than $\mathrm{NC} /$ single 61 negation readings can be correlated with a longer reaction time.

62 Finally, regarding the third and fourth questions, our experiments were designed to 63 explore whether native speakers of Catalan have a preference for $\mathrm{NC}$ readings

\footnotetext{
${ }^{2}$ See references above.
} 
64 irrespectively of the co-presence or absence of a sentential negation marker with pre65 verbal NCIs. One of our goals in raising this precise question was to seek to establish an 66 experimental base line for further investigation of the properties of Catalan NC, and in 67 particular of the factors that can bring about the emergence of DN readings, if any. A 68 second goal was to provide an experimental assessment of the strength of $\mathrm{NC}$ 69 interpretations in Catalan, for the purpose of cross-linguistic comparison with other

70 Romance languages, such as French, Italian, Portuguese and Spanish. A third goal was to 71 investigate the effects, if any, of the morpho-syntax of DP NCIs on the interpretation of 72 negative sequences. In this respect, we considered simple NCI pronominal forms vs. full

73 DPs (with both partitive and non-partitive forms), and their parallel vs. non-parallel 74 distribution in subject and object position.

75 The paper is organised as follows. Section 2 presents a summary of the relevant 76 background facts about the interpretation of negative sequences in Catalan, centring on 77 the properties of this language as a $\mathrm{NC}$ one, and on the contexts where the negative 78 marker no seems to be optional. We then present some theoretical accounts of these

79 known facts from the literature, focusing more specifically on the required ingredients of

80 a micro-parametric approach to Catalan NC. In Section 3, we present our experimental

81 design and methodology. Section 4 details the results of our experiments. Finally, Section

825 discusses these results and assesses their consequences within a general theory of NC.

\section{2. Background}

\subsection{Catalan as an NC language}


86 Negative doubling (den Besten 1986), in which multiple occurrences of morphologically

87 negative constituents are interpreted as a single logical negation, is a common synchronic

88 phenomenon in Catalan. Characteristic Catalan examples provided in (1) contain both $n$ -

89 words (Laka 1990) (ningú 'nobody', res 'nothing'), here referred to as NCIs (see footnote

90 1) and the negative marker (no 'not'):

91 (1) Ningú (no) pensa res.

92 nobody not thinks nothing

93 'Nobody is thinking anything.'

94 As is well known, no 'not' is optional with NCIs in pre-verbal position but must be 95 present with post-verbal ones, as the examples in (2), from Fabra (1956: 83), with an 96 unaccusative predicate and a pre-verbal (2a) and post-verbal subject (2b) illustrate here:

97 (2) a. Cap d'ells (no) ha vingut.

98 none of them not has come

$99 \quad$ 'None of them has come.'

100 b. ${ }^{*}(N o)$ ha vingut cap d'ells.

101 not has come none of them

102 'None of them has come.'

103 This well-known asymmetry has long fuelled the on-going debate on the status of

104 Catalan NCIs as negative quantifiers (2a) or as polarity items (2b). In their ability to

105 express a negative meaning alone when occurring in pre-verbal position (2a), or as

106 fragment answers to questions (3), Catalan NCIs show clear similarities with English

107 negative quantifiers.

108 (3) A: On vas? 
where go.2sG?

$110 \quad$ 'Where do you go?'

$111 \quad$ B: Enlloc.

$112 \quad$ nowhere

113 'Nowhere.'

114 In post-verbal positions, however, Catalan NCIs have a polar behaviour (Linebarger

115 1987; Progovac 1994; Giannakidou 1998, 2000; Martins 2000), as they are sensitive to

116 the non-veridical (Zwarts 1995) property of a c-commanding licenser or of the contexts in

117 which they felicitously occur.

118 (4) a. No ha comprat cap dels llibres. (negation)

119 not has bought none of.the ${ }_{\mathrm{PL}}$ books

120 '(S)he has not bought any of the books.'

$121 \quad$ b. Ha comprat cap dels llibres?

(question)

122 has bought any of.the $\mathrm{PL}$ books

123 'Has (s)he bought any of the books?'

124 c. Si ha comprat cap dels llibres, jo ho hauria de saber. (conditional)

125 if has bought any of.the $\mathrm{PL}_{\mathrm{PL}}$ books I it should of know

126 'If (s)he has bought any of the books, I should know it.'

127 According to traditional descriptive Catalan grammars, the combination of NCIs with

128 other NCIs or minimizers (Vallduví 1994) -otherwise known as negative spread, (with or

129 without $n o$ )- always leads to a single negation / NC reading and never to a cancellation of

130 negations into a positive meaning (Horn 1989), in contrast to what is usually found with

131 negative quantifiers for languages such as Standard English. 

nobody thinks nothing 'Nobody is thinking anything.'

(6) a. Nobody is thinking nothing.

DN

$\mathrm{DN}$

140 Catalan (5) vs. languages like English (6) that embodies the difference between Negative 141 Concord (NC) and Double Negation (DN) has been taken under some approaches 142 (Zeijlstra 2004 among others) to be the core factor of a parametric divide between NC 143 languages like Catalan, French, Italian, Portuguese and Spanish, on the one hand, and DN 144 languages like Standard English, Dutch and German, on the other hand. On this view, the 145 question arises whether DN interpretations of sequences of negative expressions are ever 146 possible in NC languages, and particularly of what, if anything, can license them. In other 147 approaches to NC (de Swart and Sag 2002), NC vs. DN readings are taken to be the two 148 ambiguous faces of the same negative sentences and thus predicted to occur in all 149 languages.

150 According to traditional descriptive Catalan grammars, DN readings are only 151 possible and in fact required when two sentential negations occur in different clauses (cf.

152 the Law of Double Negation, Horn 1989), as in (7):

153 (7) No vull que no vingui.

154 not want that not comesuBJ 
156 Yet DN is sometimes observed in single clauses under particular syntactic 157 conditions, such as for instance (8a), where an adjunct PP ambiguously allows both DN 158 and single negation/NC readings (Tubau and Espinal 2012) ${ }^{3}$. The ambiguity disappears

159 when a second no precedes the NCI in the PP adjunct, as in (8b).

160 (8) a. No lluiten per res. (DN and NC in Catalan)

161 not fight for nothing

162 'They don't fight for nothing. / They don't fight for anything.'

163 b. No lluiten per no res. (DN in Catalan)

164 not fight for not nothing

165 'They don't fight for nothing.'

166 Otherwise, special conversational, prosodic and gestural conditions are generally 167 claimed to be necessary for DN readings to emerge, be it for sequences of multiple 168 negative terms in single clauses or with isolated NCIs. Espinal and Prieto (2011), Prieto 169 et al. (2013), and Espinal et al. (in press) experimentally investigated some of the 170 prosodic and gestural factors that favour DN in Catalan and Spanish. Regarding 171 conversational conditions more particularly, Catalan DN readings were argued to emerge 172 only in discourse contexts that allow an accessible negative proposition (or 173 presupposition) - either explicitly contained in the previous discourse, or inferred from it174 to be denied (Dryer 1996, Prince 1992, Geurts 1998, Espinal and Prieto 2011). In these 175 respect, Catalan is not assumed to much differ from other NC languages, where the role

\footnotetext{
${ }^{3}$ For Tubau and Espinal (2012) this type of clause internal DN results from the presence of an abstract negative operator NEG, triggered by the NCI that checks its negative morpho-syntactic feature within this special PP construction, in combination with the overt negative marker no.
} 
176 of contextual and prosodic factors such as prosodic phrasing, stress, contrastive focus,

177 and intonation have also been highlighted as potential DN triggers (Corblin 1995, 1996;

178 and Déprez 1999, 2000 for standard French; Vinet 1998 for Québec French; Corblin and

179 Tovena 2003 for French and Italian; Molnár 1998 and Puskás 2006, 2012 for Hungarian;

180 Zanuttini 1991, 1997, Godard and Marandin 2007, and Penka 2007 for Italian; Falaus

1812007 for Romanian; Huddlestone 2010, Biberauer and Zeijlstra 2012 for Afrikaans, see

182 also de Swart 2010). Pragmatic factors can also influence the availability of DN readings

183 is some languages. For example, a DN reading is generally favoured in the following

184 French example in (9) and also possible in other languages such as Spanish, Italian and

185 Romanian:

186 (9) a. Personne ne commet aucun peché.

187 no one NEG commits no sin

$188 \quad$ 'No one commits no sin.'

189 b. Personne ne meurt jamais.

190 no one NEG dies never

$191 \quad$ 'No one never dies.'

192 Comparable facts, however, do not seem to obtain readily in Catalan NCI sequences.

193 In sum, although $\mathrm{NC}$ readings are generally thought to be the default reading for 194 sequences of negative expressions, DN readings are also sometimes possible, but 195 generally argued to emerge only under a narrow set of circumstances not yet fully 196 understood but quite generally held to be exceptional in some ways.

198 2.2. The role of no 
199 This section focuses on the role of the sentential marker no 'not' in Catalan negative

200 sentences. As a preliminary, note that first and foremost, the Catalan sentential negative

201 marker no is the linguistic form that encodes the monadic negative operator $\neg$ and

202 expresses an interpretable negative formal feature.

203 In sentences containing NCIs in pre-verbal positions, as noted above, no is always

204 possible, but not systematically required. The source of this optionality remains unclear.

205 On the one hand, traditional prescriptive grammars of Catalan encourage the use of no

206 with pre-verbal NCIs to distinguish non-negative uses of NCIs from negative ones as in

207 the following examples from Fabra (1912: 218), since the presence of no here appears to

208 make a meaning difference.

209 (10)a. Si mai vinguéssiu, què farien ells?

210 if ever come $_{\text {SUBJ }}$ what do COND $_{\text {they }}$

211 'If you ever came, what would they do?'

212 b. Si mai no vinguéssiu, què farien ells?

213 if ever not comesuBJ what do COND $_{\text {Shey }}$

214 'If you never came, what would they do?'

215 On the other hand, descriptive grammars of contemporary Catalan claim that, if pre-

216 verbal NCIs are focalized (the capital letters stand for emphasis), then no is preferably

217 explicit (Espinal 2002: 2766, exs, $(106 \mathrm{~b}, \mathrm{c})$ and $(107 \mathrm{~b}, \mathrm{c})):^{4}$

218 (11)a. Ningú (no) ha vist res.

\footnotetext{
${ }^{4}$ As will be clear later in the paper, it turns out that traditional and descriptive grammars of Catalan only describe one of the varieties encountered in our empirical investigation, namely the variety we will label Variety A, whose speakers mainly use polar NCIs and have a non-negative use of no. As explicit in our Results section, the current paper also considers the empirical facts and theoretical soundness of a different variety, Variety B, whose speakers use negative quantifiers in focalized positions and have a regressive use of non-negative $n o$.
} 
nobody not has seen nothing

$220 \quad$ 'Nobody has seen anything.'

b. NINGÚ no ha vist res. nobody not has seen nothing

'Nobody has seen anything.'

(12)a. Enlloc (no) es veia ni una anima.

nowhere not CL saw not a soul

'Nowhere was a soul to be seen.'

b. NI UNA ÀNIMA no ha vist.

not a soul not has seen

'Not a soul has (s)he seen.'

230 Espinal (2002: 2767) further states that the negativity of a sentence is intensified

231 when the negative marker is explicit, (13). Moreover, she also notes that the tendency to

232 prefer an overt negative marker increases as the distance between the pre-verbal NCI and

233 the verb gets larger (14).

234 (13) De cap manera no vull que em deixis diners.

235 of no way not want that me $e_{\mathrm{DAT}}$ lend money

236 'By no means do I want you to lend me money.'

237 (14) Cap de les plantes que vam deixar a la banyera abans

238 none of the plants that PAST leave in the bathtub before

239 de marxar de vacances no sembla que s'hagi mort.

240 of leave of holidays not seem that CL.hassuBj died 
'None of the plants that we left in the bathtub before leaving on holidays seems to have died.'

243 These facts suggest that the prosodic phrasing of the pre-verbal NCI along no may be of

244 relevance in influencing its presence. Notwithstanding the precise conditions of its 245 appearance, the sentential negative marker no is quite generally assumed to have no polar

246 semantic effect on the overall interpretation of these type of sentences. In particular, no in 247 such contexts is not taken to contribute an additional semantic negation.

248 In sum, while prescriptive grammars recommend the use of a negative marker no in

249 pre-verbal position of negative sentences generally, descriptive grammars acknowledge

250 that native speakers hesitate on the use of no after pre-verbal NCIs (Solà 1973: 97,

251 Espinal 2002: 2767). The reasons of this hesitation are not well understood, but could 252 well reflect sociolinguistic factors, such as age, language dominance of the speaker's area 253 of living, and percentage of use of Catalan in daily life. According to Vallduví (1994: 254273 , note 8), the optionality of no "is a matter of register". And indeed, the current 255 tendency in spoken Catalan and in the media-variety is to omit the negative marker.

256 Espinal (2007) interestingly observed that a comparable optionality and lack of polar 257 semantic effect in the use of the negative sentential marker no is also found in other 258 Catalan sentence types, namely in contexts of so-called expletive negation (EN). EN 259 "refers to a pleonastic (paratactic or redundant) use of negation that does not modify the 260 truth value of the proposition in which it appears (Jespersen 1917; Vendryes 1950; Martin 261 1984; Muller 1991)" (Espinal 2007: 51). Characteristic Catalan examples are given in 262 (15), with the optional expletive negative marker in parentheses and the lexical trigger of 263 EN in italics: 
264 (15)a. Abans que (no) arribi l'amfitrió, deixeu que em presenti.

265 before that not arrive $_{S U B J}$ the.host let that me introduce ${ }_{S U B J}$

266 'Before our host arrives, let me introduce myself.' (Espinal 2007: 50, ex. (1a))

267 b. La policia evità que (no) hi hagués un accident.

268 the police stopped that not $\mathrm{CL} \operatorname{had}_{\text {SUBJ }}$ an accident

269 'The police prevented an accident.'

270 c. Gasta més ell en tres mesos que (no) tu en tot l'any.

271 spends more he in three months that not you in whole the.year

272 'He spends more in thres months that you in a year.'

$273 \quad$ (Espinal 2002: 2777, ex. (136a))

274 d. Va prometre que s'esperaria fins que el seu xicot

275 PAST promise that CL.wait until that the his boyfriend

276 (no) tornés de la guerra.

277 not come.back from the war

278 'She promised to wait until her boyfriend came back from the war.'

$279 \quad$ (Espinal 2002: 2777, ex. (136b))

280 For Espinal $(1991,1992)$ and van der Wouden (1994a, 1994b), expletiveness is a

281 semantic effect that obtains in Logical Form when the semantic property of specific

282 syntactic constituents (either the negative marker no or an NCI) is absorbed by the

283 semantic contribution of another expression in the context. As illustrated in (15),

284 expletive no is licensed under non-veridical contexts, under conditions that quite parallel

285 those of polarity licensing. As Espinal suggests the expletive negation of (15) may well

286 be a type of polarity dependency comparable to the one observed in (16) with NCIs. 
(16) a. Abans que ningú digui res, deixeu-me donar-vos la benvinguda. before that nobody saysuBJ nothing let.me give.you the welcome Before anyone says anything, let me welcome you.' (Espinal 2007: 50, ex. (1b))

'The police prevented that an accident.'

295 strikingly parallel those of the optional no with pre-verbal NCIs. There is comparable 296 optionality, and the hesitation or register variety of use observed in the Catalan

297 population seems to cross both of these constructions equally, and presumably along the 298 same patterns. This commonality of occurrence clearly suggests that both phenomena 299 should profitably receive a parallel account. In particular both the optionality of no, when 300 in co-occurrence with pre-verbal NCIs, and the expletiveness of no in the context of 301 specific lexical triggers suggest that Catalan could manifest two homophonous distinct 302 lexical variants of no, one semantically negative and the other not, akin to the lexical 303 distinction found in French between the semantically negative marker pas and the 304 expletive negative marker ne. This is indeed what Espinal and Tubau (to appear) propose, 305 as is further discussed below. The existence of two distinct lexical negations is also 306 defended for Afrikaans by Biberauer (2008, 2009, 2012). Biberauer (2013) gives the 307 following list of properties distinguishing the two:

\begin{tabular}{|l|l|l|}
\hline Property & $\mathrm{Nie}_{1}$ & $\mathrm{Nie}_{2}=$ expletive \\
\hline Omission $\rightarrow$ meaning change (polarity reversal) & Yes & No \\
\hline
\end{tabular}




\begin{tabular}{|l|l|l|}
\hline Modifiability & Yes & No \\
\hline Substitution by emphatic negator & Yes & No \\
\hline Stressability & Yes & No \\
\hline
\end{tabular}

Table 1. Properties to distinguish between semantically negative and expletive nie in

310 These properties, which are clearly reminiscent of those of the two distinct negation 311 markers found in French, pas and ne, also obtain in Catalan.

312 In an attempt to explain away the optionality of no, Van der Wouden and Zwarts

313 (1993: 216-7) were to our knowledge the first to hypothesize the existence of a dialectal

314 variation. According to them, "there exists one dialect of Catalan that parallels French (or

315 Afrikaans) in the sense that a doubling element no (that may express negation on its own)

316 is always obligatory whenever negative elements show up in the sentence, and another

317 dialect that behaves like Italian, with doubling only from post-verbal positions".

318 According to this description, in one dialect (Variety I) no is always obligatory, whereas

319 in the second one (Variety II) no is only obligatory to license post-verbal NCIs.

320 However, contrary to these claims, recent work by Espinal and Tubau (2014) 321 concluded (i) that Variety I does not exist, since there is no variety of Catalan for which 322 no is always obligatory, and (ii) that Variety II does not characterize any dialect at all, 323 since all post-verbal NCIs, PIs and minimizers, can be licensed by the negative marker, or 324 by an NCI in pre-verbal position. We take up this issue further in our discussion section, 325 after the results of our experiment have been presented. But first, we briefly summarize 326 recent theoretical approaches that propose an account for this specific issue, as well as for 327 the other properties of Catalan NC described above. 


\subsection{Theoretical background}

330 The literature on $\mathrm{NC}$ is vast, with two main issues traditionally articulating the

331 discussion. One is the negative force of NCIs; the other is their quantificational status.

332 NCIs have been claimed to be universal quantifiers, both negative (Zanuttini 1991,

333 Haegeman and Zanuttini 1991, among others) and non-negative (Giannakidou 2000),

334 non-negative polarity items (Bosque 1980, Laka 1990, among others), and indefinites,

335 both negative (Suñer 1995) and non-negative (Ladusaw 1992, 1994, Zeijlstra 2004,

336 Tubau 2008, among others). Other accounts have cast NCIs as numerals of cardinality

337 zero (Déprez 1997b, 2000, and following; Espinal 2000a) with underspecified

338 quantificational force, or as items that are ambiguous between weak negative polarity

339 items and strong negative polarity items (Martins 2000), or ambiguous between polarity

340 items and negative quantifiers, either lexically (Herburger 2001) or structurally (Déprez

341 1997b, 2000, 2011a, b; Déprez and Martineau 2004). Theoretical approaches to NC are

342 always narrowly linked to the status proposed for NCIs, but as a proper review of this

343 abundant literature would take us too far afield, here we restricted our focus on the most

344 prominent recent accounts that have made a specific proposal regarding Catalan NC.

345 Before presenting the micro-parametric approach to NC recently developed in Espinal

346 and Tubau (to appear), we oppose two views, namely the macro-parametric account in

347 Zeijlstra (2004) and subsequent work, and the polyadic quantification approach of de

348 Swart and Sag (2002).

$350 \quad$ 2.3.1. A macro-parametric account: Zeijlstra (2004)

351 For Zeijlstra (2004 and subsequent work) the phenomenon of $\mathrm{NC}$ is nothing but the 352 realization of a syntactic agreement (formalized under Chomsky's (1995) Agree 
353 operation) between a single negative operator (which can be overt or abstract) carrying an

354 interpretable negative formal feature, [iNeg], and one or more elements carrying an

355 uninterpretable negative feature, [uNEG]. For him, NCIs are semantically non-negative

356 indefinites that carry an uninterpretable negative feature [uNEG] that must be checked by

357 an interpretable negative feature [iNEG] on a semantic negation. Zeijlstra $(2004,2008)$

358 further argues that $\mathrm{NC}$ languages are distinguished from DN languages by a macro-

359 parameter that states that the former have a formal negative feature, while in the latter the

360 negative feature has no formal status but is purely semantic. This macro-parametric

361 variation is formalized as in (17):

$362(17)$

363

a. NC: $[\mathrm{u} / \mathrm{iNEG}] / \mathrm{X}$

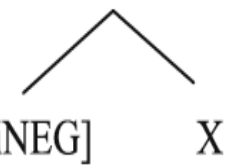

b. No NC: $\quad \mathrm{X}$

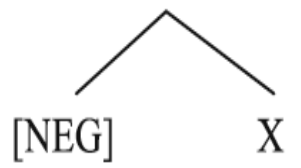

364 To further distinguish among varieties of NC languages, such as Strict and Non-

365 Strict NC languages (Giannakidou 1998), Zeijlstra assumes that negative markers can

366 differ as negative expressions do in DN vs. NC languages, in being either semantically

367 negative (i.e., [iNeg]) in Non-Strict NC languages, or semantically non-negative (i.e.,

$368[\mathrm{uNeg}])$ in Strict NC languages. This yields the typology in Table 2.

\begin{tabular}{|l|l|l|}
\hline & $\begin{array}{l}\text { n-words (=NCI) semantically } \\
\text { negative }\end{array}$ & $\begin{array}{l}\text { n-words (=NCI) semantically non- } \\
\text { negative }\end{array}$ \\
\hline $\begin{array}{l}\text { Negative markers semantically } \\
\text { negative }\end{array}$ & $\begin{array}{l}\text { DN languages: } \\
\text { Dutch, German, Swedish }\end{array}$ & $\begin{array}{l}\text { Non-strict NC languages: } \\
\text { Spanish, Italian, Portuguese }\end{array}$ \\
\hline $\begin{array}{l}\text { Negative markers semantically } \\
\text { non-negative }\end{array}$ & Afrikaans A & $\begin{array}{l}\text { Strict NC languages: } \\
\text { Czech, Serbo-Croation, Greek, } \\
\text { Afrikaans B }\end{array}$ \\
\hline
\end{tabular}

Table 2. Biberauer and Zeijlstra's (2012) typology of NC and DN languages

370 With respect to this typology, as Zeijlstra (2004) notes, Catalan appears to be a 
371 misfit because of the optional occurrence of its negative marker, which is neither

372 obligatory as in Strict NC languages, nor limited to co-occur with only post-verbal NCIs

373 as in non-Strict NC languages. In an effort to reduce this Catalan misfit to the NC

374 patterns observed elsewhere, Zeijlstra (2004) follows Van der Wouden and Zwarts (1993:

375 216-7) in claiming that the Catalan negation optionality flags the existence, side by side,

376 of two distinct varieties. For him, Variety I, on the one hand, has Strict NC characterized

377 by the obligatory presence of no for NCIs in all syntactic positions, in similarity with

378 Greek and Romanian. Variety II, on the other hand, must disallow no with pre-verbal

379 NCIs, as it features Non-Strict NC, in similarity with Italian and Spanish. On this view, 380 the optionality of $n o$ is illusory.

381 Zeijlstra's approach makes very clear empirical predictions. First and foremost, it 382 predicts that in a NC language, DN should simply not arise. Furthermore, for Catalan in 383 particular, speakers of Variety I should find sentences lacking no with pre-verbal NCIs to 384 be as ungrammatical as they are in other Strict NC languages. For speakers of Variety II, 385 in contrast, sentences featuring a pre-verbal NCI with no should be ungrammatical or 386 have a systematic DN reading, as reported for in Non-Strict NC languages. These 387 predictions, however, do not accord with the traditional descriptions of Catalan 388 summarized above where sentences with pre-verbal NCIs that lack no are considered 389 grammatical for all speakers and where the co-presence of no is quite generally assumed 390 to leave the solid NC interpretation of sentences with NCIs fully unaltered. Our 391 experiments meant to verify these predictions.

393 2.3.2. The polyadic quantification approach of de Swart and Sag (2002) 
394 In contrast to Zeijlstra (2004 and following), de Swart and Sag (2002) and de Swart 395 (2010) take NCIs to always be negative quantifiers. For them, NC corresponds to one 396 interpretation that is afforded by the interaction of these negative quantifiers in a polyadic 397 quantifier framework (van Benthem 1989; Keenan and Westerståhl 1997). On this 398 approach, there is no parametric distinction between NC and DN languages, since every 399 sentence involving multiple negative elements can receive both a resumptive and an 400 iterative interpretation. The first corresponds to a $\mathrm{NC}$ reading, the second to a DN 401 reading. However, while $\mathrm{NC} / \mathrm{DN}$ ambiguities for multiple negative constructions are 402 well attested in French and Romanian (i.e., languages for which independent resumption 403 analyses were respectively proposed by Déprez 1997b, 2000; Falaus 2007; and 404 Iordăchioaia 2010), in other languages commonly exhibiting NC, no comparable 405 systematic ambiguity has so far been reported, and DN readings are quite generally 406 thought to only arise under restrictive and unusual contextual conditions, as discussed 407 above for Catalan. Thus, for a resumption analysis to be able to account for cross408 linguistic variations in NC, an additional mechanism must be assumed. To tackle NC 409 typological differences, de Swart (2010) proposes to embed her resumptive analysis in a 410 bidirectional optimality framework. Her analysis of Catalan involves the interaction of 411 five constraints presented below:

$412 *$ MaxNeg: Mark the argument of a negative chain.

413 NegFirst: Negation is pre-verbal (Jespersen 1917, Horn 1989).

$414 \quad$ MaxSN: A negative clause must bear a marker of sentential negation.

$415 *$ Neg: Avoid negation in the output. (Markedness constraint).

416 InterpretNeg (IntNeg): Interpret all neg expressions in the input as contributing a 
negative meaning in the output.

418 We reproduce here the crucial OT tableaus that pertain to Catalan (de Swart 2010:173-

419 174). The order from right to left in the tableau reflects the ranking of the constraints.

420 Note that, in the tableau in (18), it is the high ranking of the NegFirst constraint that

421 enforces the obligatory presence a pre-verbal marker of sentential negation with post-

422 verbal Catalan NCIs (de Swart's n-words), as in Italian, Spanish or Brazilian Portuguese.

$423 \quad(18)$

Tableau 9 Generation of Catalan/Brazilian Portuguese with postverbal n-word

\begin{tabular}{|l|l|c|c|c|c|c|}
\hline $\begin{array}{l}\text { Meaning } \\
\neg \mathrm{V} \exists \mathrm{x}\end{array}$ & Form & MAXNEG & NEGFIRST & MAXSN & $*$ NeG & INTNEG \\
\hline & V neg & & $*$ & $*$ & $*$ & \\
\hline & SN V neg & & & & $* *$ & \\
\hline
\end{tabular}

With pre-verbal NCIs, in contrast, looking at the tableau in (19), since it is the NCI that

426 satisfies the NegFirst constraint, the output is derived through the competition between

427 the lower ranked constraints MaxSN and *Neg. If MaxSN and *Neg are unranked with

428 respect to each other, as indicated here by the doted vertical line in the tableau in (19)

429 below, the grammar generates two optimal outputs. This is what is assumed to derive the

430 optionality of no with pre-verbal NCIs described by traditional Catalan grammars.

$431 \quad(19)$

Tableau 10 Generation of Catalan/Brazilian Portuguese with preverbal n-word

\begin{tabular}{|r|l|l|c|c|c|c|}
\hline $\begin{array}{l}\text { Meaning } \\
\neg \exists \mathrm{x}_{1} \mathrm{~V} \exists \mathrm{x}_{2}\end{array}$ & Form & MAXNEG & NEGFIRST & MAXSN & *NEG & INTNEG \\
\hline ( & neg V neg & & & $*$ & $* *$ & \\
\hline & neg SN V neg & & & & $* * *$ & \\
\hline
\end{tabular}

434 De Swart (2010) also argues that the possibility of two distinct dialects is derivable on her

435 approach if, instead of being unranked, MaxSN and *Neg are ranked. If MaxSN

436 dominates *Neg, then no will be obligatory with the input or tableau (19) as in the 
437 Variety I described by Zeijlstra (2004). The reverse domination of these two constraints

438 produces a dialect were no is disallowed again as in Zeijlstra's Variety II. We note here

439 that although this approach predicts both the optionality of no described by traditional

440 Catalan grammars and the possibility of the two dialects distinguished by Zeijsltra and

441 Van den Wouden, it does not, however, predict what to expect with respect to the

442 distribution of DN vs. NC readings in either of the two varieties. Regarding

443 interpretation, De Swart states that in her account, both dialects are NC ones with the

444 ranking *Neg $>>$ IntNeg in the semantics, so that sentences with and without a marker of

445 sentential negation are interpreted as conveying single negation under both grammars. In

446 short, de Swart predicts a variety of possible grammatical outputs for Catalan, but does

447 not match these distinct outputs to distinct interpretations.

449 2.3.3. The micro-parametric approach

450 In contrast to de Swart and Sag (2002) and de Swart (2010, and following), Déprez

451 (1997b, 2000, and ff.) and Déprez and Martineau (2004) argue that the resumption 452 analysis proposed in May (1990) for English negative sequences is a restricted form of

$453 \mathrm{NC}$ that can be available only in constructions or languages in which NCIs are true 454 negative quantifiers. But, importantly, Déprez argues that this type of resumptive analysis 455 should not be generalized across all NC constructions or languages, since NCIs, like all 456 other types of indefinite expressions can have distinct semantic and syntactic nature and, 457 consequently, be subject to various interpretative and licensing conditions. Déprez 458 (1997b) posits the existence side by side of two basic types of NC that form the opposite 459 extremes of the cross-linguistic spectrum of possibilities, one, being a pure resumption 460 type, and the other essentially equivalent to NPI licensing (non-veridical licensing). Both 
461 types can entertain mixed and complex interactions in distinct $\mathrm{NC}$ constructions, within

462 single languages or cross-linguistically, depending on the nature of the NCIs involved in

463 particular negative sequences. This approach derives a non-uniform, intricate and

464 nuanced landscape for NC dependencies, with variations expected within and across

465 languages, according to the nature of the NCIs. See in particular Déprez (2011b) for a

466 recent development of this approach. In short, Déprez proposes to combine the semantic

467 ingredients of the above discussed two approaches within a micro-parametric framework

468 where the choice of one or the other type of NC, resumption or NPI licensing (with NPIs

469 of possibly distinct strength), is determined by the nature and the internal morpho-syntax

470 semantic mapping of the NCIs that a particular language or negative sequence

471 comprises. ${ }^{5}$

472 A specific micro-parametric approach that takes into account the possibly variable

473 nature of the negative elements involved in a negative sequence has independently been

474 developed for Catalan in the works of Espinal (2000a) and, more recently, Espinal and

475 Tubau (to appear). In this section we present the ingredients of this micro-parametric

476 approach to Catalan NC. This approach suggests that the difference between the two

477 varieties of Catalan presented earlier (namely Variety I and Variety II) is based on

478 ambiguity, not only, with respect to the nature of NCIs, but also regarding the negative 479 marker.

480 As mentioned above, to account both for the possibility of EN and the optional 481 occurrence of the sentential marker no with pre-verbal NCIs, Espinal and Tubau propose 482 that Catalan has two homophonous lexical variants for the sentential negative marker no.

\footnotetext{
${ }^{5}$ More specifically, Déprez (1997a, b, 2000) and Déprez and Martineau (2004) link variation in NC to the internal structure of NCIs, arguing that the closer an NCI occurs to the edge of the constituent that contains it, for instance a DP-shell, the stronger its negative force.
} 
483 (20)a. $n o_{1}$ : semantic negation; formally specified [iNEG] (Zeijsltra 2004, ff.).

$484 \quad$ b. $n o_{2}$ : expletive negation; formally specified with a strong $[+\sigma]$ feature that is 485 characteristic of polar items and characterizes semantically dependent items 486 (Chierchia 2006, Labelle and Espinal 2014). ${ }^{6}$

487 Moreover, along with previous ambiguity accounts for NCIs (Déprez 2000, and ff.;

488 Martins 2000; Herburger 2001), they further propose that Catalan NCIs come in two

489 varieties as well, a dependent NCI type and a negative quantifier, each specified as

490 follows:

491 (21)a. $\mathrm{NCI}_{1}$ : polarity indefinite meaning characterized $[+\sigma]$.

492 b. $\mathrm{NCI}_{2}$ : indefinite negative quantifiers meaning $\neg \exists$.

493 Espinal and Tubau (2014) additionally posit two varieties of Catalan that respectively

494 have the following distribution of negative markers and NCIs. In Variety A, where the

495 negative marker is optional with pre-verbal NCIs, NCIs are most often polarity items

496 assumed to be endowed with a semantic feature, $[+\sigma]$, which induces domain-widening

497 and needs to be licensed by an appropriate semantic operator (Chierchia 2006, Labelle

\footnotetext{
${ }^{6}$ A reviewer is especially interested in the semantic contribution of EN within Catalan NCI sequences in comparison to other syntactic contexts. Espinal $(1992,2000 \mathrm{~b}, 2007)$ defends that in EN contexts (e.g. the Catalan verb dubtar 'to doubt', the preposition abans 'before') the licenser is an expression whose logical instructions force to consider a negative state of affairs, and the licensed constituent is either a negative marker of the weak type (Catalan and Spanish no, French ne) or a PI (pure PIs and NCIs). More specifically, Krifka (2010) and Delfitto (2013) defend that so-called EN is in fact negatively interpreted under the scope of German bevor 'before', since it yields the complement of the set of times that represents the unnegated proposition. Similarly, in Delfitto and Fiorin (2014) the authors hypothesize that the role of the negation occurring in exclamatives and rhetorical questions is to impose an order of informativity upon a hierarchical structure of accessible propositions: only when negation is high (e.g., clitic negation in Paduan) it conveys a biased interpretation and reverses the order of informativity, in such a way that the proposition that is more likely to be true is the one that is as close as possible to the top of a propositional hierarchical structure (that is, they express some sort of universal quantification). It should be pointed out, however, that EN is also common in Catalan wh-exclamatives, even though this language lacks clitic negation. In Espinal $(1992,200 \mathrm{~b}, 2007)$ it is hypothesized that EN in any syntactic context can be analysed as a regular negative marker that can be logically absorbed when a set of lexical and structural conditions are met. At this moment, we acknowledge that different analyses of EN and various phenomena associated with EN are available in the linguistic literature, but motivating which alternative is more appropriate for the negative marker that occurs with pre-verbal NCIs in Catalan is beyond the scope of the paper.
} 
and Espinal 2014). Espinal and Tubau (to appear) further argue that these can participate

499 in NC structures because they undergo a process of word syntax that allows the feature

$500[\mathrm{uNeg}]$ to merge with their root specified as $[+\sigma]$. Once $[\mathrm{uNeg}]$ is part of a polar NCI, it

501 requires a licensor specified as [iNeg] to Agree with. ${ }^{7}$ Alternatively, in Variety A, NCIs

502 may also be existential negative quantifiers, but this seems to be an emergent possibility

503 that is less common than the use of non-negative NCIs. Finally, Variety A distinguishes

504 two negative markers, one which is inherently negative, specified with the formal feature

505 [iNeg], and another one which is expletive and carries also a polarity $[+\sigma]$ feature

506 (Espinal and Tubau to appear).

507 In Variety B, in contrast, the negative marker is fundamentally semantically negative

508 and, hence, specified as [iNeg]; the expletive negative in this variety is basically non-

509 existent (and hence specified as 'regressive' in Table 3). Furthermore, in this variety there

510 are also two different lexical entries for NCIs, as postulated in (21), which are in

511 competition. As negative existential quantifiers, $\mathrm{NCIs}_{2}$ are endowed with an inherent

512 Focus feature [uFoc], which (following Déprez 2011b) is assumed to require DP internal

513 movement of the $\mathrm{NCI}_{2}$ to the left periphery of the DP. Espinal and Tubau's (2014, to

514 appear) assumptions for Catalan NCIs and negative marker(s) are summarised in Table 3.

\begin{tabular}{|l|c|c|}
\hline Catalan & NCIs in negative contexts & Negative marker(s) \\
\hline Variety A & $1 .[+\sigma]$ & $1 .[\mathrm{iNeg}]$ \\
& $2 . \neg \exists,[\mathrm{uFoc}]($ emergent) & $2 .[+\sigma]$ \\
\hline Variety B & $1 .[+\sigma]$ & $1 .[\mathrm{iNeg}]$ \\
& $2 . \neg \exists,[\mathrm{uFoc}]$ & $2 .[+\sigma]$ (regressive) \\
\hline
\end{tabular}

Table 3. Lexical variation in NCIs and the negative marker in Catalan

516 Having surveyed various formal accounts of Catalan we now turn to discuss our

\footnotetext{
${ }^{7}$ Following Espinal and Tubau (to appear) what this means is that polar NCIs are assumed to be semantically non-negative, but syntactically active to participate in NC structures. Polar NCIs start as roots defined $[+\sigma]$, and, in the course of the derivation, these roots can merge with a [uNeg] feature to build a complex item.
} 
517 experimental design before we consider the results of our two experiments.

\section{3. Methods}

520 Recall from the introduction that we designed two experiments aimed at exploring four

521 questions; first, whether NC is always the default preferred interpretation for sequences

522 of multiple negative elements in Catalan; second, whether the processing of NC is faster

523 than that of DN; third, whether the co-presence of the negative marker no could influence

524 the readings of NCI sequences and boost DN readings, as predicted by Zeijlstra (2004),

525 and fourth, whether morpho-syntactic conditions and syntactic order could influence the

526 emergence of DN readings. Overall, these questions can be understood as pertaining to

527 the general issue of whether semantically non-compositional $\mathrm{NC}$ readings have a general

528 unmarked status for the interpretation of sequences of negative expressions as compared

529 to compositional $\mathrm{DN}$ readings.

530 To investigate our four questions, we designed two experiments in which subjects

531 had to match a verbal stimulus with a visual one. In Experiment 1, the sentential negative

532 marker no was absent after pre-verbal NCIs whereas in Experiment 2 the critical items as

533 well as one of our control conditions (the control NPI condition) had the negative

534 sentential marker no 'not' after pre-verbal NCIs. Thus the verbal stimuli submitted to the

535 participants of the two experiments only differed in absence vs. presence of no 'not' in

536 the set of critical items and the NPI control condition. Speakers were asked to choose

537 between two pictures representing distinct scenes the one that best corresponded to the 538 meaning of the sentence they were presented with in written form on a computer screen. 
539 The design was a preference test and the task a picture selection one. This section of the

540 paper details our experimental protocol.

541 Section 3.1 presents the participants. Section 3.2 describes the materials used in our

542 experimental design, as well as the structure of the design. Section 3.3 explains the

543 procedure with which the experiment was run. Finally, Section 3.4 presents the statistical

544 model that was used to analyse our results.

546 3.1. Participants

54770 native speakers of Catalan (58 women and 12 men, aged between 19-61 with a 548 majority between 20-23), mostly students and staff at the Universitat Autònoma de

549 Barcelona, participated in the two experiments. Our subjects were mostly from the 550 Barcelona area, but some of them were from other parts of the Catalan-speaking 551 territories. To take into consideration potential dialectal variations, speakers were asked 552 to answer a brief sociolinguistic questionnaire at the end of the experiment. In this 553 questionnaire, participants were asked about sex, age, place of birth and living area for 554 the past 10 years and their daily use of Catalan. Our sample population, however, was 555 not balanced for these factors. Answers to these questions were codded as follows:

556 (22)a. Regular use of Catalan in daily life: yes, no

557 b. Percentage of Catalan use: plus $75 \%$, minus $75 \%$

$558 \quad$ c. Sex: male, female

559 d. Age: $18-24,25-34$, more than 35

560 d. Birthplace: Central (CEN), Occidental (OCC), and Other (OTH) 
562 Metropolitan (CENnotMET), and Other (OTH)

563 It should be pointed out that Catalan speakers know both Catalan and Spanish, and show

564 different degrees of dominance of the two languages. In our subject population, Catalan

565 dominance (understood as the self-perceived amount of use of Catalan in the speaker's

566 daily life) was reported to be over $75 \%$ for $70 \%$ of our subjects, $50-75 \%$ for $27.14 \%$ of

567 our subjects, and between $20-50 \%$ for only $2.86 \%$. In sum, the great majority of our

568 participants predominantly used Catalan in their daily interactions. ${ }^{8}$

569 Subjects were randomly assigned to one of the two experiments. 35 speakers took

570 Experiment 1 without no 'not' (31 women and 4 men, aged between 20-59), and 35

571 speakers (27 women and 8 men, aged between 19-61) took Experiment 2 with no 'not'.

573 3.2. Materials

574 The experimental material comprised 96 stimuli sentences matched to two pictures each

575 subdivided into 8 conditions: 4 critical conditions, 4 control conditions and 4 different

576 filler conditions. There were 8 token sentences for each condition, totalling 32 critical

577 items, and 32 control items. In addition, 32 filler items were also presented. Each verbal

578 stimulus was matched with two pictures representing scenes between which the subjects

579 were asked to select, by mouse clicking, which one best represented the meaning of a

580 sentence visually presented on a computer screen.

\footnotetext{
${ }^{8}$ A reviewer asked whether it would have been possible to test separately Catalan speakers from those that also speak Spanish. As Spanish is part of the education system of Catalan speakers and widely present in the media, it is virtually impossible to find native speakers of Catalan with no knowledge of Spanish.
} 
582 obtain a balanced item presentation and avoid (i) ordering effects, (ii) stimuli repetition,

583 whether visual or verbal, and (iii) left-right effects for the choice of pictures. 8 distinct

584 lists of 8 blocks with 12 distinct stimuli sentences each were created. In each list, the

585 order of presentation of the 8 blocks was distinct. Each block of 12 sentences was further

586 subdivided into 4 sub-blocks each containing 3 sentences, with random ordering between

5871 critical, 1 control and 1 filler sentence.

588 The speakers were presented with two scenes, each representing a situation that 589 corresponded to a distinct reading of the sentence. A sample visual stimulus is given in 590 Figure 1 for Experiment 1 (without no), and in Figure 2 for Experiment 2 (with no).

591

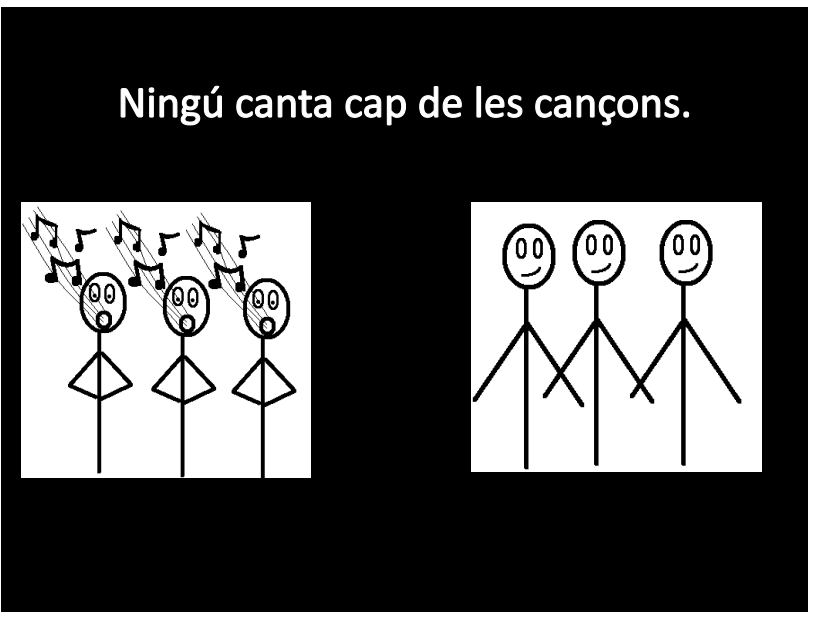

593 Figure 1. Slide used in Experiment 1 (without no). The text translates literally as

594 'nobody sings none of the songs'. The image on the right is true for the NC or single

595 negation interpretation of the sentence, the one on the left represents the DN reading. 596 


\section{Ningú no canta cap de les cançons.}

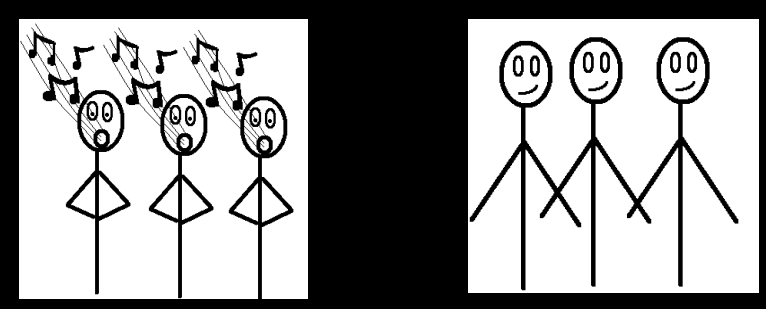

Figure 2. Slide used in Experiment 2 (with no). The text translates literally as 'nobody not sings none of the songs'. The image on the right corresponds to a $\mathrm{NC}$ or single

600 negation interpretation of the sentence (i.e., 'Nobody sings any of the songs') and the one

601 on the left to a DN reading cancelling out to a positive statement (i.e., 'Nobody doesn't sing none of the songs'; that is, Everybody sings some song).

603 For Figure 1 and 2, we expected speakers interpreting the target sentence as meaning

604 'Nobody sings any of the songs', i.e., an NC reading, to click on the right picture, and 605 speakers interpreting it as 'Nobody sings none of the songs', i.e., an DN reading to click 606 on the left picture.

607 The sentences used in the two experiments were organised as follows: four critical 608 conditions, which featured sequences of two NCIs that vary in internal syntactic 609 complexity (simple pronouns -encoded Pro- vs. full noun phrases -encoded DP-), their 610 syntactic position (pre-verbal or post-verbal), and parallelism (same NCI type in pre611 verbal and post-verbal position, distinct NCI type in both positions). This yielded the 612 following four combinations: critical DP DP, critical Pro Pro, critical Pro DP and critical 613 DP Pro. 
614 Items exemplifying these four critical conditions contained the four different 615 combinations of NCIs listed and illustrated in (23), where DP means that the NCI has 616 both a prenominal Specifier and a noun phrase or a partitive complement, and Pro means 617 that the NCI is a one-word pronominal form. Since sample sentences in Experiment 1 618 (without no) and Experiment 2 (with no) only differed with respect to the presence vs. 619 absence of the sentential negative marker no 'not', this is indicated in (23) by means of 620 parentheses.

621 (23) Critical DP DP (parallel complex)

622 a. Cap dels alumnes (no) llegeix cap llibre.

623 none of.the students (not) reads no book

$624 \quad$ 'None of the students reads any book.'

625 Critical DP Pro (non-parallel complex subject)

626 b. Cap dels nens (no) beu res.

627 none of.the children (not) drinks nothing

628 'None of the children drink anything.'

629 Critical Pro DP (non-parallel simple subject)

630 c. Ningú (no) canta cap de les cançons.

631 nobody (not) sings none of the songs

632 'Nobody sings any of the songs.'

633 Critical Pro Pro (parallel simple)

634 d. Ningú (no) trenca res.

635 nobody (not) breaks nothing

$636 \quad$ 'Nobody breaks anything.' 
637 The four control conditions are listed and illustrated in (24). The control DN 638 condition was introduced to test the capacity of speakers to produce DN readings in 639 unambiguous biclausal sentences containing two sentential negative markers. We 640 reasoned that speakers that could not get DN readings in these unambiguous cases would 641 not get DN readings in our critical conditions. As it turns out, one of our participants in 642 Experiment 2 failed this control (with a 100\% error) and was removed from further 643 analysis.

644 The control Universal Quantifier was introduced to test the capacity of speakers to 645 interpret sentences with universal quantifiers in subject position in combination with 646 existential quantifiers in post-verbal position; we reasoned that DN readings can logically 647 correspond to Universal Quantifier readings (i.e., if there is something that none of the 648 characters in the pictures do not do, then this is something that all of them in fact do). 649 Thus, we needed to check that participants could independently get such readings. 650 Sentences exemplifying this control were judged as true of a pictorially represented 651 situation where a specific action was performed by all the characters in the picture.

652 The control Negative Quantifier set of sentences aimed to check the capacity of 653 native speakers to associate a single negation reading to sentences with only one pre654 verbal NCI. Both Experiment 1 (with no) and Experiment 2 (without no) shared the same 655 set of sentences.

656 Finally, control NPI aimed to check the interpretation associated with pre-verbal 657 NCIs followed by an indefinite expression, without no 'not' in Experiment 1 and in 658 combination with no 'not' in Experiment 2. Both are equally described as conveying a 
659 single negation interpretation in traditional and descriptive grammars of Catalan, where 660 no is described as simply optional.

661 (24) Control DN

662 a. No és el cas que els turistes no pesquin cap peix.

663 not is the case that the tourists not fish no fish

664 'It is not the case that the tourists did not catch any fish.'

$665 \quad$ Control Universal Quantifier

666 b. Tothom mou alguna cosa.

667 everybody moves some thing

$668 \quad$ 'Everybody moves something.'

$669 \quad$ Control Negative Quantifier

670 c. Ningú perd les claus.

$671 \quad$ nobody loses the keys

$672 \quad$ 'Nobody loses the keys.'

$673 \quad$ Control NPI

674 d. Ningú(no) neteja alguna cosa.

675 nobody not cleans some thing

$676 \quad$ 'Nobody cleans something.'

677 A set of the 32 filler sentences (four fillers per critical sentences) meant to distract 678 the participants from focusing on negative sentences. A sample of these items is given in 679 (25), with various combinations of nominal expressions in pre-verbal and post-verbal 680 position of a transitive verb: with definite or indefinite articles, demonstratives, bare 681 plurals, positive indefinite quantifiers, and a few more sentences with universal 
682 quantifiers as objects.

683 (25) a. Els nens miren un programa.

684 the children watch a programme

685 'The children watch a programme.'

686 b. Aquests convidats beuen sucs.

687 these guests drink juices

$688 \quad$ 'These guests drink juice.'

689 c. Uns turistes pesquen aquests peixos.

690 some tourists fish these fish

$691 \quad$ 'Some tourists catch these fish.'

692 d. Cada home tiba una caixa.

693 every man pulls a box

$694 \quad$ 'Every man pulls a box.'

695

696 3.3. Procedure

697 Participants were individually seated in a quiet computer room at the Universitat 698 Autònoma de Barcelona. The stimuli presentation used the Neurobehavioral Systems'

699 Presentation 17.0 software. Participants were presented with a set of instructional slides,

700 the body of the experiment, and a final sociolinguistic questionnaire on their age, sex,

701 birthplace, current place of living, and amount of Catalan use. Participants were

702 instructed to read aloud the stimulus sentences as naturally as possible, and then press the

703 space bar to display the relevant two pictures on the screen. The reading was recorded 
704 and the stimulus sentence remained on the screen to prevent confusion. ${ }^{9}$ Picture choice

705 was made by mouse click on the centre of the picture. Mouse trajectory and time to

706 picture choice were measured, starting from the moment when the pictures appeared to

707 the choice click. From time to time (approximately every 10 pictures) participants were

708 asked to explain their choice orally responding to the question: why this choice? The

709 experimenter listened to these responses. A total of 6,624 responses were obtained, 3,360

710 for Experiment 1 (32 critical +32 controls +32 fillers x 35 participants), and 3,264 for

711 Experiment 2 (32 critical +32 controls +32 fillers $\times 34$ participants). Each of the

712 experiments lasted approximately between 10 and 15 minutes.

715 The responses were analysed using a Generalized Linear Mixed Model fit by maximum

716 likelihood (R packages lme4, Bates et al. 2014a, 2014b, and multcomp, Hothorn et al., 717 2008) with a logistic regression (logit). Picture choice was recorded with two measures:

718 mouse tracking (trajectory) from centre point, and mouse clicking (the final choice). The

\footnotetext{
${ }^{9}$ The reading was recorded to allow for subsequent prosodic analysis. Note that since in our design, the presentation of stimuli sentences was visual, participants were free to produce the prosodic contour they thought best fit the interpretation they chose. It is thus expected that the prosodic realisation of NC vs. DN readings could differ as a reflection of the interpretation given by participants to the sentence stimuli. A pitch track analysis of the prosodic contour produced by our subjects could thus turn out to be particularly revealing for the question of whether interpretation correlates with prosody, since it would allow us to compare the prosody of NC choices to that of DN. At present, however, since this analysis is not completed, discussion of the prosodic realisation must be left for further research. It must be noted, however, that in our design, prosody can in no way alter the results reported here. It could reflect our participants' choice of interpretation (and it hopefully does), but it could not be the source of it or influence it, since it was not given to our participants, but it was produced by them as a function of their chosen interpretation.

In addition, no information was given to the participants regarding the pragmatic setting against which the sentence could be interpreted. That is, the experiment did not contain any explicit contextual information that deliberately favoured the emergence of DN readings. Clearly, as noted by a reviewer, the fact that we provided no context does not entail that participants did not make one up for themselves. But in this respect our experimental design does not differ from any experimental setting in which speakers are asked to evaluate sentences without a context.
} 
719 time between picture appearance (after bar-pressing) and picture choice (by mouse

720 clicking on the picture chosen) was also recorded.

721 In the next section we report our results on picture choice (NC / single negation vs.

722 DN interpretation for our critical items, and true vs. false for the control conditions and 723 fillers), as well as on the time that the choice took for distinct readings. A prosodic

724 analysis of the recorded readings and a quantitative analysis of the mouse trajectory have 725 been left for future analysis.

\section{Results}

728 In this section, we start by considering responses to our control items represented in

729 Figure 3.

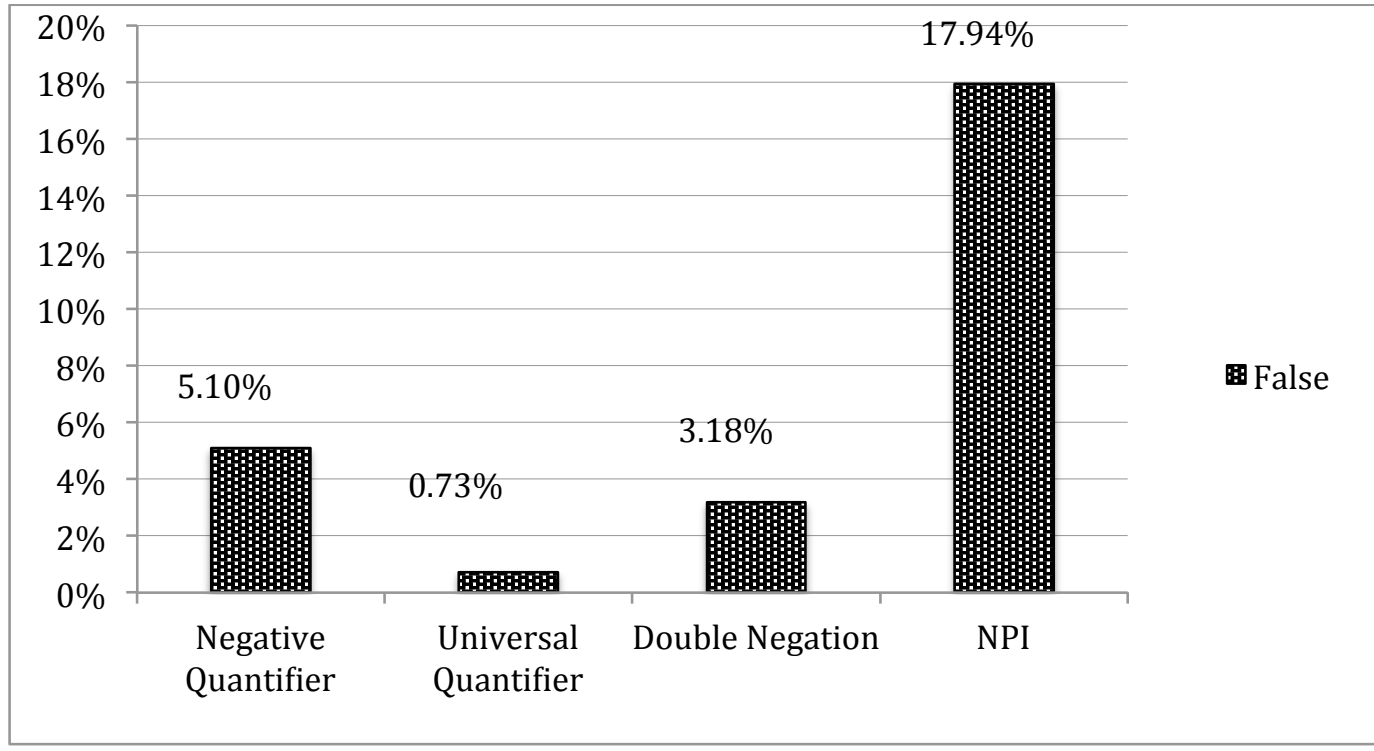

Figure 3. Percentage of error in the expected interpretation of control conditions in Experiment 1 (without $n o$ ) and Experiment 2 (with $n o$ ).

Figure 3 shows the percentage of errors participants made under the control

734 conditions described in Section 3.2 above. Considering the overall results of the two

735 experiments together, the total percentage of errors on control items amounted to $6.88 \%$ 
736 of the responses. For the Negative Quantifiers control the percentage of errors was at

$7375.10 \%$. For the Universal Quantifier control it was $0.73 \%$ and for the Double Negation

738 control (i.e., those with the complex double proposition structure in (24a)) it was $3.18 \%$.

739 Notably, this control was entirely failed by one of our participants ( $100 \%$ error), who was

740 then removed from all further analyses. Finally, for the NPI control, we note that the rate

741 was distinctly higher with $17.94 \%$ of errors.

742 This much higher error rate requires clarification. Recall that the above results put

743 together the controls for the two experiments, since in both cases, the assignment of

744 speakers to Experiment 1 (without no) or Experiment 2 (with no) was random, so that no

745 group difference was expected, and the tested items were all identical, except for the NPI

746 control. Concerning the NPI control, for Experiment 2 (with no), we opted to add no 'not'

747 to the NPI control sentences. ${ }^{10}$ This choice was guided by the following reasoning:

748 without no our NPI sentences, which sports a single NCI in pre-verbal position followed

749 by an indefinite in post-verbal position, like Cap serventa trenca un gerro (lit. no servant

750 breaks any vase), are unambiguous and only have a single negation reading. As described

751 by traditional Catalan grammars, and as is the case for our native speaker co-authors, the

752 addition of the sentential negation marker no to such sentences should leave their

753 meaning unaffected. On this view, then, the addition of no should have left the validity of

754 our unambiguous control unaffected. As it turns out, however, this was clearly not the

755 case in our experiment. Thus while in Experiment 1 (without no) the percentage of errors

756 on NPI control was a low $2.90 \%$, as expected, confirming the unambiguity of such

757 sentences, it was an unexpected high $32.50 \%$ in Experiment 2 (with no). The addition of

758 no in fact strongly affected the speakers' choice, allowing a DN reading to surface from

\footnotetext{
${ }^{10}$ This was not done for the other control items, as it was not pertinent.
} 
759 the combination of the pre-verbal NCI with the added no and creating an ambiguity, such

760 that the NPI sentence type could no longer be considered a control item. Rather than

761 errors, indeed, it turned out that our participants' choice of picture reflected a clear DN

762 reading, where the negation of the pre-verbal NCI was cancelled by sentential no,

763 contrary to the predictions drawn from traditional Catalan descriptions. We return to this

764 important point in more detail below, where we opted to consider this condition along

765 with our other critical conditions.

766 Returning to Figure 3 above, it is important to note that when the results for control

767 NPI receive separate consideration, the overall percentage of errors drops to $3.20 \%$. This

768 is an overall low rate that clearly shows that the task was well understood by the

769 participants, who had little difficulty picking the picture representing the relevant

770 meaning of the sentences they were presented with. Even if the sentences containing

771 NCIs had a more elevated rate of errors than the Universal Quantifier control condition, it

772 remains low enough to validate the experimental design.

773 Let us now turn to considering our overall results on critical items in both

774 Experiment 1 (without no) and Experiment 2 (with no). Consider first Figure 4, which

775 shows the percentage of $\mathrm{NC}$ vs. DN interpretation overall, all critical conditions 776 confounded.

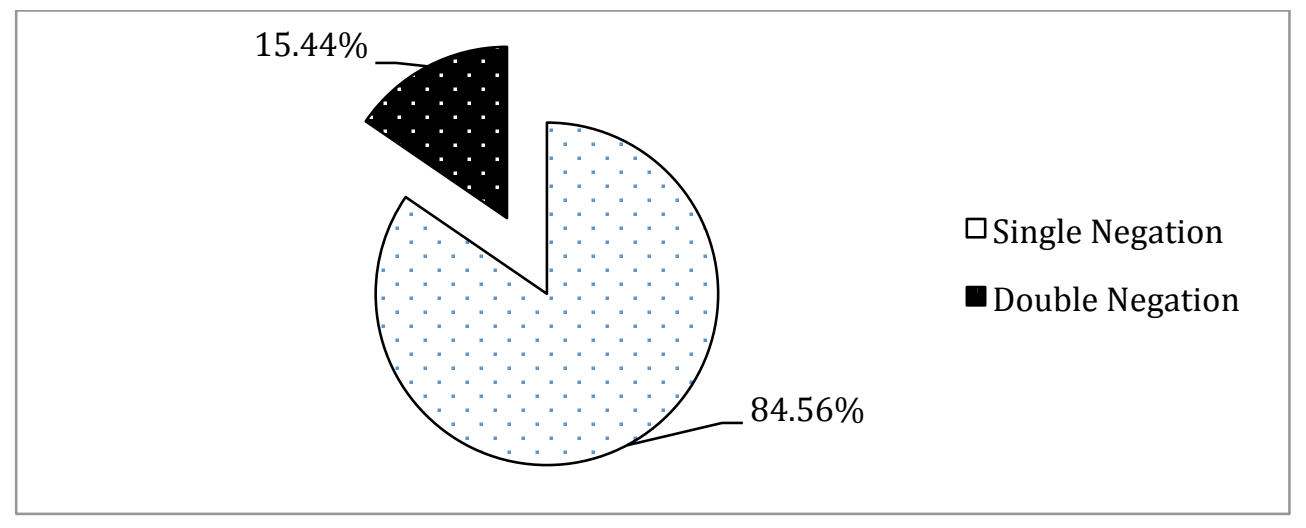


Figure 4. Total percentage of NC / single negation readings vs. DN readings in Experiment 1 (without $n o$ ) and Experiment 2 (with $n o$ ) confounded.

780 Figure 4 shows clearly that the choice for NC / single negation is undoubtedly the 781 preferred reading for simple transitive sentences with two argument NCIs in Catalan. 782 Taking into account all critical items for both experiments, $84.56 \%$ of the responses show 783 a choice for the NC reading. The comparison between NC / single negation readings vs.

784 DN readings indicate the rate of prominence of $\mathrm{NC}$ choice in a solid NC language.

785 Choice for a DN interpretation was, overall, $15.44 \%$ and is thus clearly the dis-preferred 786 interpretation choice. It is worth emphasising, however, that beyond this clear preference, 787 our results also indicate that DN readings are far from being entirely absent in either 788 experiment, an observation that we detail below.

789 Figure 5 shows that DN readings emerge somewhat differently in all our critical 790 conditions, which feature simple transitive sentences that contain negative expressions of 791 different syntactic complexity distributed in pre-verbal and post-verbal positions. This 792 figure again collapses the results of both Experiment 1 (without no) and Experiment 2 793 (with no) together. Eyeballing Figure 5 as compared to Figure 4, it is rather clear that the 794 amount of DN in both experiments largely exceeds the amount of errors in our control 795 conditions. A Wilcoxon rank sum test shows that the overall proportion of DN is greater 796 than the proportion of errors in Fillers $(\mathrm{p}<0.001)$. The choice for DN, then, cannot merely 797 be attributable to errors. 


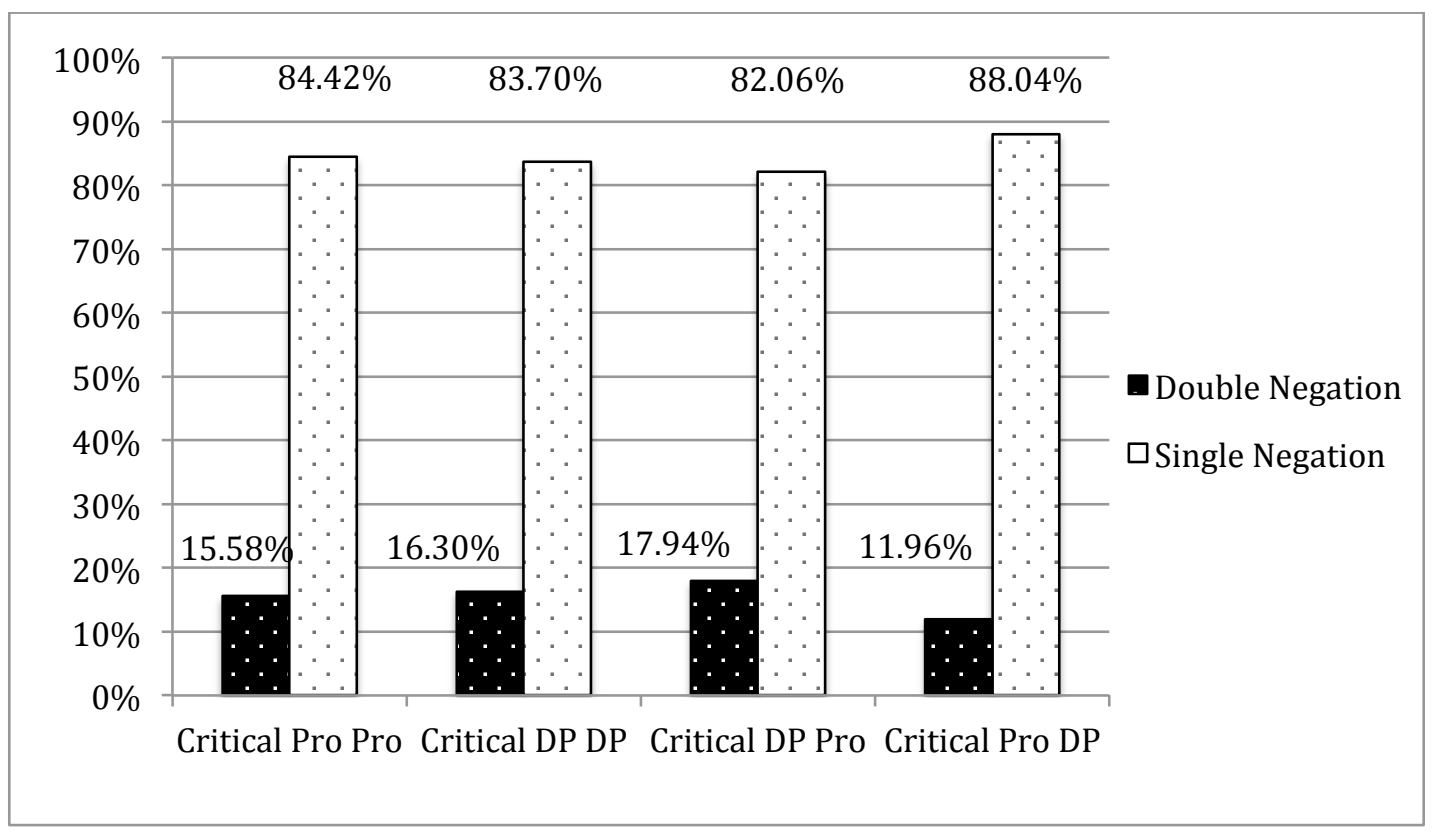

799 Figure 5. Percentage of NC / single negation interpretation and DN interpretation in

800 critical conditions with different syntactic complexity in Experiment 1 (without no) and Experiment 2 (with no) confounded.

802 It should be noted, however, that across both experiments, 23 of our 69 participants (4 in

803 Experiment 2) never chose a DN reading in any and all the critical conditions plus the

804 NPI control. Such results clearly provide overwhelming empirical support to the claims in 805 the literature that DN is a marked interpretation for Catalan NCI sequences

806 When considering the results of both experiments separately, we find that in 807 Experiment 1 (without no) only a small number of DN readings (6.34\%) were obtained 808 for all our critical items overall. This result does not appear to strongly differ from the 809 rate of errors noted in our control conditions and, thus, could plausibly be attributed to 810 mistakes. To confirm this, we conducted pairwise comparisons using a Wilcoxon rank 811 sum test with Holm correction. The comparison of DN responses in our critical 
812 conditions to the number of errors in the controls and fillers lead no statistically

813 significant difference with a $\mathrm{p}=1$ value.

814 Notably, however, the presence of the sentential negative marker no severely

815 increased DN interpretations in Experiment 2 (with no), with the percentage of DN

816 reading climbing to $24.29 \%$ across the four critical conditions. This figure is far too high

817 to be attributable to error.

818 A GLMM analysis was run over our entire data set with perceived DN as the 819 dependent variable. The random factors were 'subject' and 'sentence'. The fixed factors

820 were 'Experiment' (without no vs. with no) and 'Condition' (critical DP DP, critical Pro

821 Pro, critical DP Pro, critical Pro DP). First and foremost, a massive effect of the presence

822 of no was observed $(\mathrm{p}<0.001)$.

823 In Experiment 1 (without no), the random factor 'Sentence' had little effect 824 (Variance $=0.1754)$, whereas the effect of the factor 'Subject' was higher (Variance $=$ 825 3.9156). Comparing the four critical conditions with the control NPI yielded significant

826 effects in two conditions: these were critical DP Pro $(\mathrm{p}<0.00206)$ and critical Pro Pro $827(\mathrm{p}<0.00504) .{ }^{11}$ This indicates that these are the conditions that most favoured DN 828 readings when tested items only contained interacting NCIs but no sentential negative 829 marker. Concerning these effects, however, it needs to be kept in mind that overall the 830 level of DN in Experiment 1 (without no) is not significantly different from the level of 831 errors in our control conditions as noted above.

\footnotetext{
${ }^{11}$ In this GLMM analysis, the control NPI was taken as the reference of comparison because it was formally the closest to the critical conditions in that the items in this control were not combined with a preverbal no in Experiment 1 (without no) but were in Experiment 2 (with no), in similarity with the critical items.
} 
832 Comparing the critical conditions among themselves by means of Tukey Contrasts

833 Multiple Comparisons of Means (Tukey 1953), we obtained significant effects between

834 critical DP Pro and critical Pro DP ( $\mathrm{p}=0.0174)$, as well as, between critical Pro Pro and

835 critical Pro DP ( $\mathrm{p}=0.0398)$. Additionally, the contrast between critical DP DP and critical

836 DP Pro is significant at $\mathrm{p}<0.1$. This indicates an overall $\mathrm{DN}$ enhancing effect of DP in

837 pre-verbal position as compared to Pro.

838 For Experiment 2 (with no) there was little effect of the random factor 'Sentence'

839 (Variance $=0.003822$ ), as in Experiment 1 (without $n o$ ), whereas for the factor 'Subject',

840 the effect was much higher (Variance $=4.528526)$. This indicates that the variation

841 among subjects was higher, a point we return to below when discussing subject data.

842 Statistical significant effects were obtained in three critical conditions when these were

843 compared with the control NPI: critical Pro DP ( $<<0.001)$, critical Pro Pro $(p<0.001)$, and

844 critical DP Pro $(\mathrm{p}<0.001)$. This indicates that these are the conditions that most differed

845 from the control NPI in terms of how they influenced the rate of DN response. Critical

846 Pro DP was the condition that resulted in the least amount of DN responses, as compared

847 to control NPI that manifested the highest rate, followed by the critical Pro Pro condition

848 and the critical DP Pro condition. After NPI, the condition that most favoured DN was

849 DP DP, which showed no significant difference with the control NPI.

850 We further conducted a Tukey Contrasts Multiple Comparisons of Means (Tukey

851 1953) analysis to compare the four critical conditions among themselves with the aim of

852 finding out which one favoured a DN reading more in Experiment 2 (with $n o$ ). The

853 output of this test was that the critical conditions that yielded a significant difference

854 were critical Pro DP as compared to the condition critical DP DP $(\mathrm{p}=0.04616)$. In this 
855 case, the latter condition was the one that showed the most DN readings. This suggests

856 that a complex DP in pre-verbal position is a significant factor that favours DN readings.

857 Consider now Figures 6 and 7, which provide the results of DN readings obtained for

858 the critical conditions in Experiment 1 (without no) and in Experiment 2 (with no),

859 respectively, as compared with the NPI condition. For Experiment 1 (without no), the

860 condition that produced the most DN readings is the critical DP Pro, followed by critical

861 Pro Pro, critical DP DP and finally critical Pro DP. Recall, however, that the low levels of

$862 \mathrm{DN}$ in this experiment are not significantly different from error rates in the control

863 conditions. $^{12}$

864

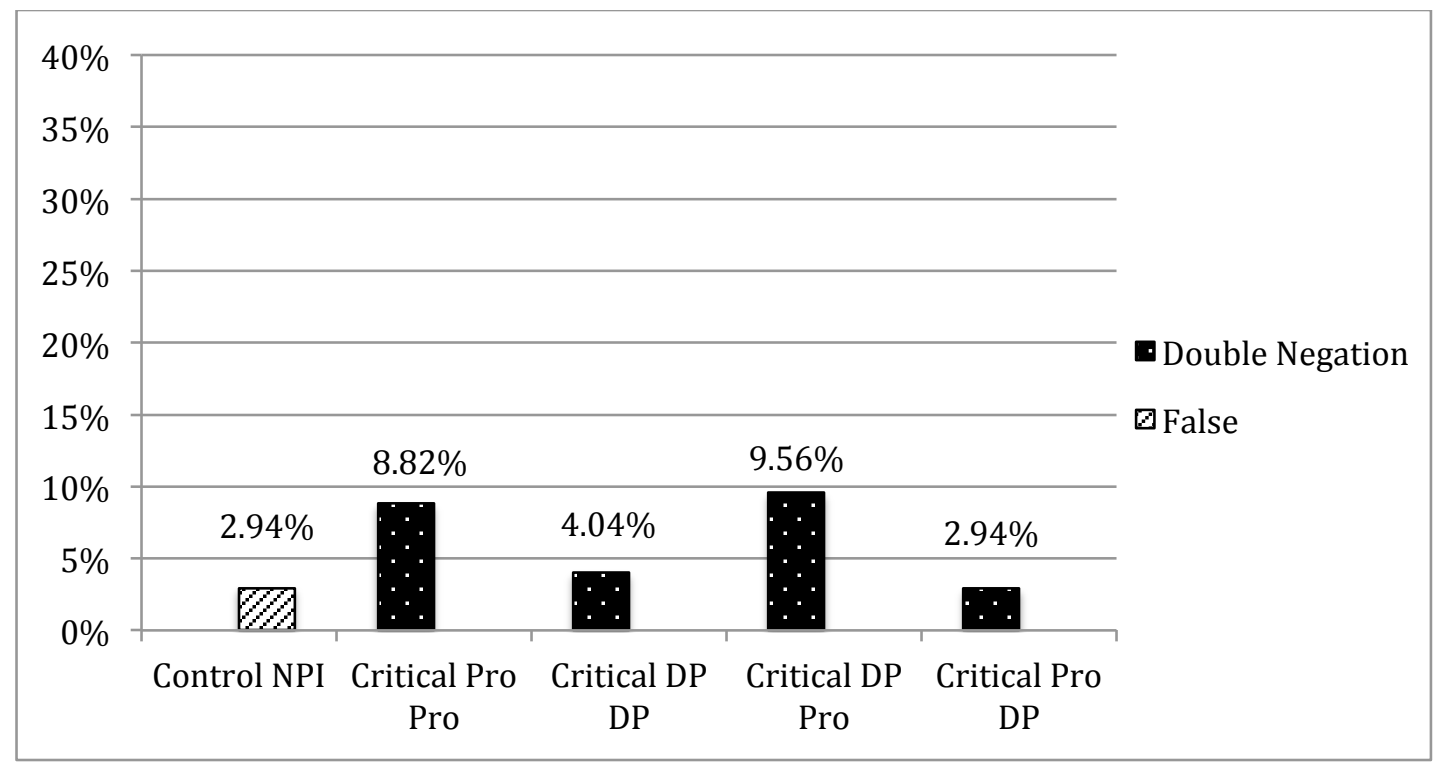

865 Figure 6. Percentage of DN interpretation in critical conditions in Experiment 1 (without no) as compared to the NPI control.

\footnotetext{
${ }^{12}$ A finer analysis (GLMM over Experiment 1 alone) showed a significant effect only when comparing the DP Pro condition and the Pro Pro condition against the control Universal Quantifier condition, which was the control in which the speakers had the least amount of error. No significant effect is obtained when comparing to the control DN or even the control Negative Quantifier.
} 
868 compared to this control, the next highest rate of DN is observed in the critical DP DP

869 condition, followed by the critical DP Pro condition, the critical Pro Pro condition and the

870 critical Pro DP condition. This leads an apparent effect in favor of increased DN when

871 the subjet of the transitive sequence is a DP.

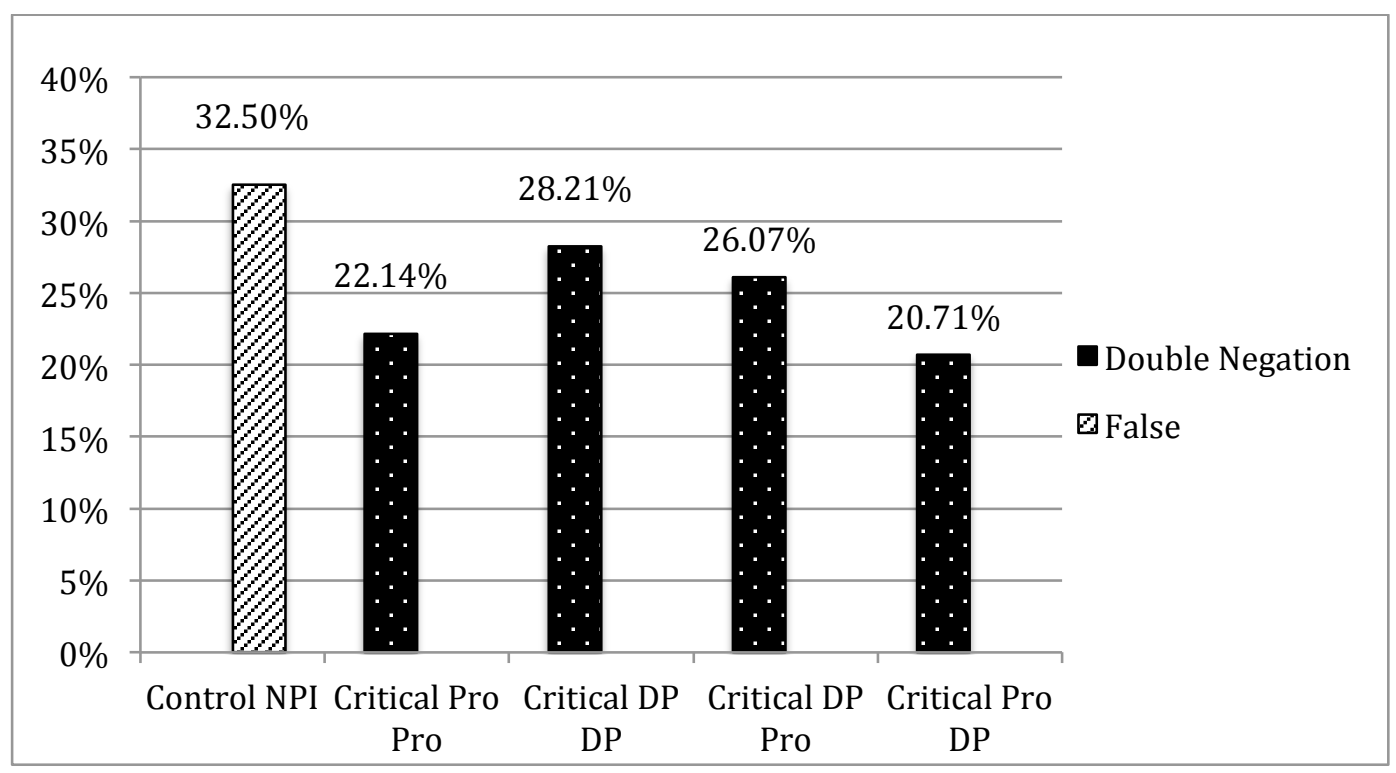

873 Figure 7. Percentage of DN interpretation in critical conditions in Experiment 2 (with no) as compared to the NPI control.

875 For Experiment 2 (with no) a further binomial comparison was conducted to 876 compare sequences with parallel morpho-syntactic structures, i.e., conditions that had two

877 NCIs of the same morpho-syntactic structures (parallel), to sequences with non-parallel 878 NCIs. Figure 8 compares the critical conditions DP DP and Pro Pro (=parallel) together 879 to the critical conditions Pro DP and DP Pro (=non-parallel). The effects of parallelism 880 were not found to be significant. For clarification, this comparison was conducted 881 because it was suggested in May (1990), that parallel sequences of quantifiers may favour 882 a resumptive quantification reading. This suggestion was not confirmed in our data, 
883 presumably because of the otherwise DN enhancing effect of DP in pre-verbal position 884 (see below), which in all likelihood interfered in the above comparison.

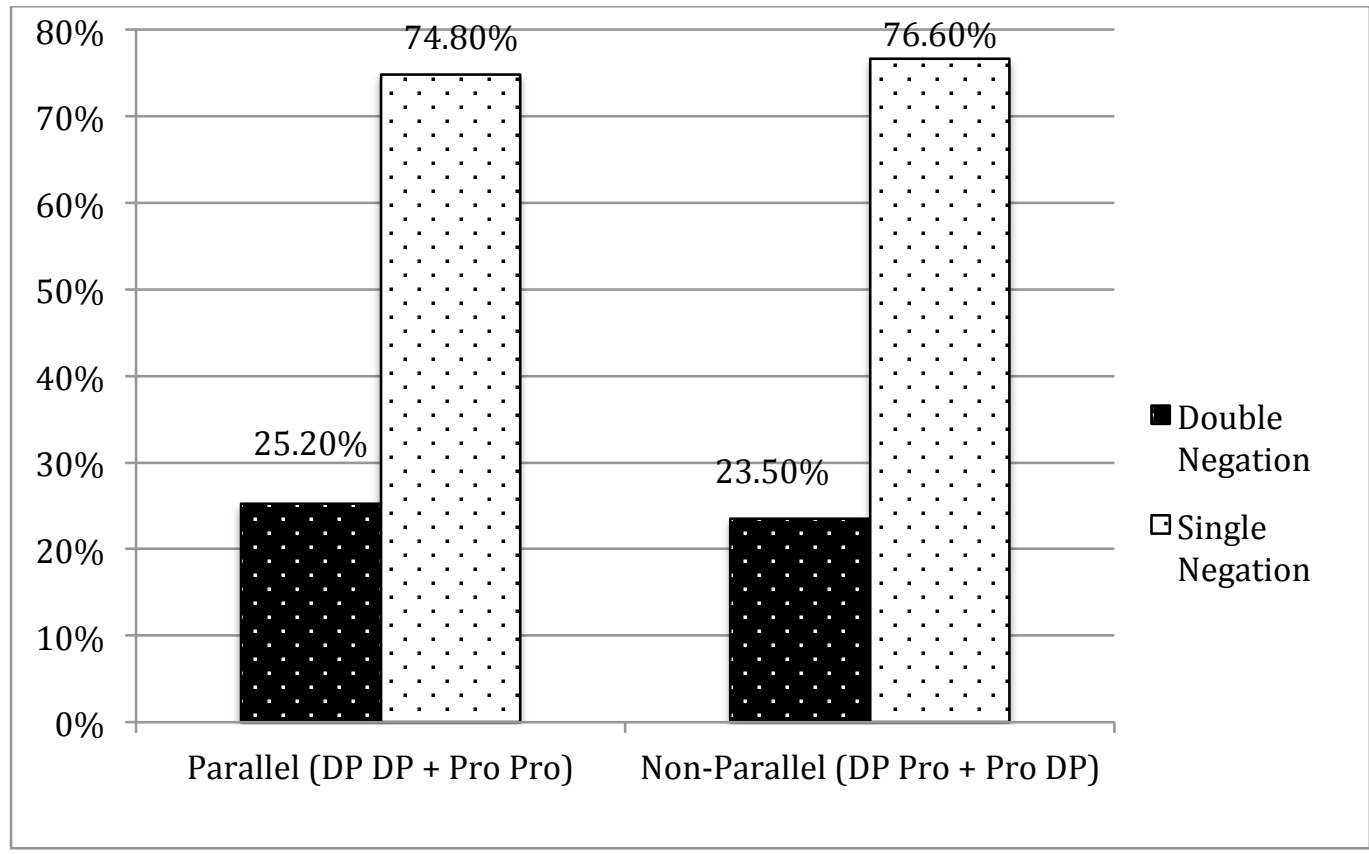

886 Figure 8. Parallelism effect in the responses to critical conditions (critical DP DP and critical Pro Pro) in Experiment 2 (with no).

A further analysis was conducted to determine the effect of the complexity of the 889 negative expression in both pre-verbal (Figure 9) and post-verbal (Figure 10) positions.

890 Figure 9 reveals that the complexity of negative expressions in pre-verbal position clearly

891 favors DN readings. A t-test comparison reveals that the difference between conditions in 892 which a DP is in pre-verbal position (DP DP and DP Pro) significantly increases the rate 893 of DN in comparison to conditions in which Pro is in pre-verbal position (Pro DP, Pro 894 Pro $)(\mathrm{p}<0.001)$. 


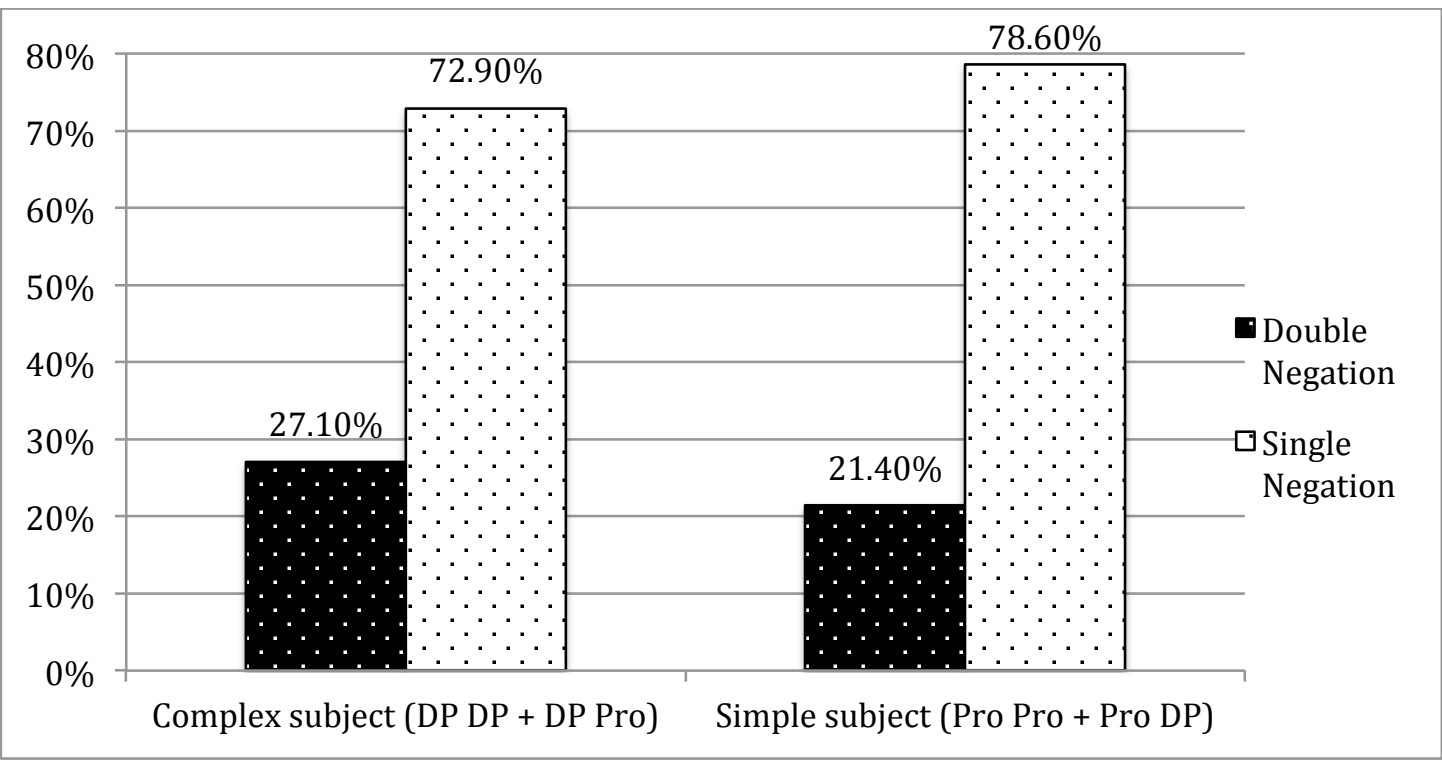

Figure 9. Complexity effects of negative expressions in pre-verbal position in

898 By contrast, the complexity of negative expressions does not matter in post-verbal 899 position as shown in Figure 10.

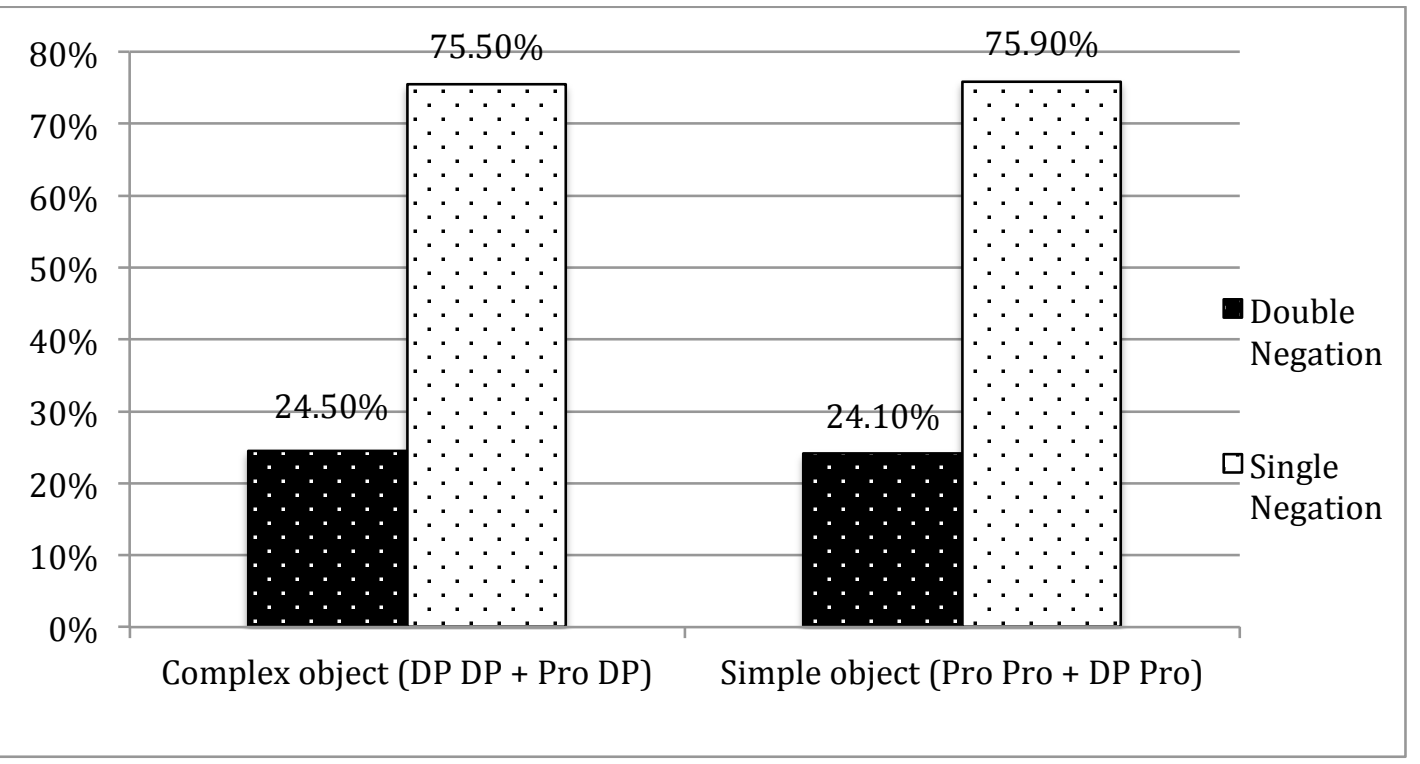

901 Figure 10. Complexity effects of negative expressions in post-verbal position in 
903 Let us finally turn to individual subject results. Figure 11 reports the percentage of

904 DN responses per subject in the critical and NPI conditions of Experiment 2 (with no).

905 This Figure reveals that 4 subjects had no DN interpretation at all, that 15 participants

906 had between $1-10 \%$ of $\mathrm{DN}$ responses, 5 between $10-25 \%$ DN readings and that 11

907 participants had between 40 and $90 \%$ DN responses. The overall picture appears to be

908 one in which there are essentially two populations, one (the largest) with participants

909 hardly or infrequently responding with a DN choice and the other where the DN choice

910 represents a clear option that cannot be ignored.

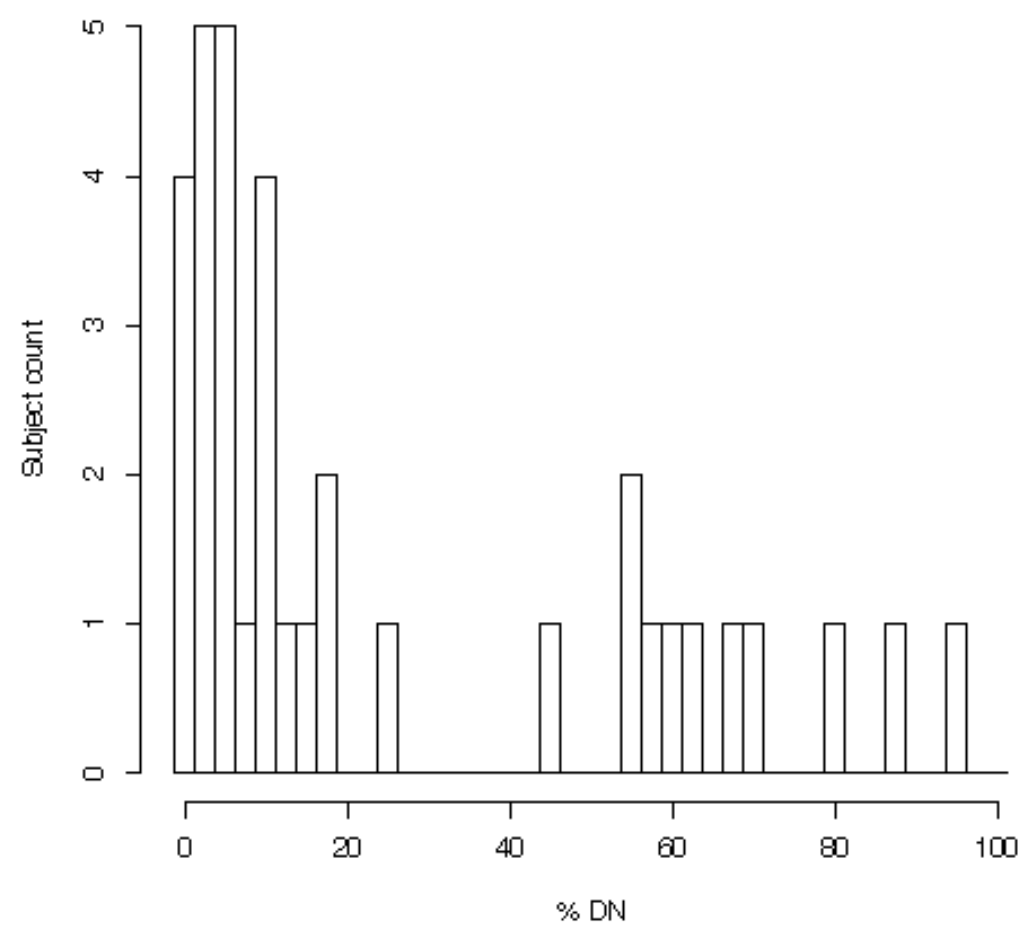

911

912 Figure 11. Distribution of number of DN readings with respect to number of subjects in

913 Experiment 2 (with $n o$ ).

914 A final remark is of interest concerning our subject data. Recall from the Methods

915 section that our subjects filled up a small questionnaire at the end of their participation 916 concerning their place of birth, current living location, age range, sex and percentage of 
917 Catalan use in their daily life. In general, the overall population was not sufficiently

918 balanced for any of these factors to produce a significant effect on the linguistic results.

919 Nevertheless, one factor that had a suggestive effect nearing significance was the

920 percentage of Catalan use in daily life. As the figure below reveals, there was overall less

921 DN interpretation in Experiment 2 (with $n o$ ) for subjects that used Catalan in their daily

922 life between $75 \%$ of the time or more. This suggests that the speakers that used Spanish

923 more frequently in their daily lives were also the ones who tended to have more DN

924 interpretations. But to be confirmed, such a tendency would need to be examined in an

925 experiment with a balanced subject population.

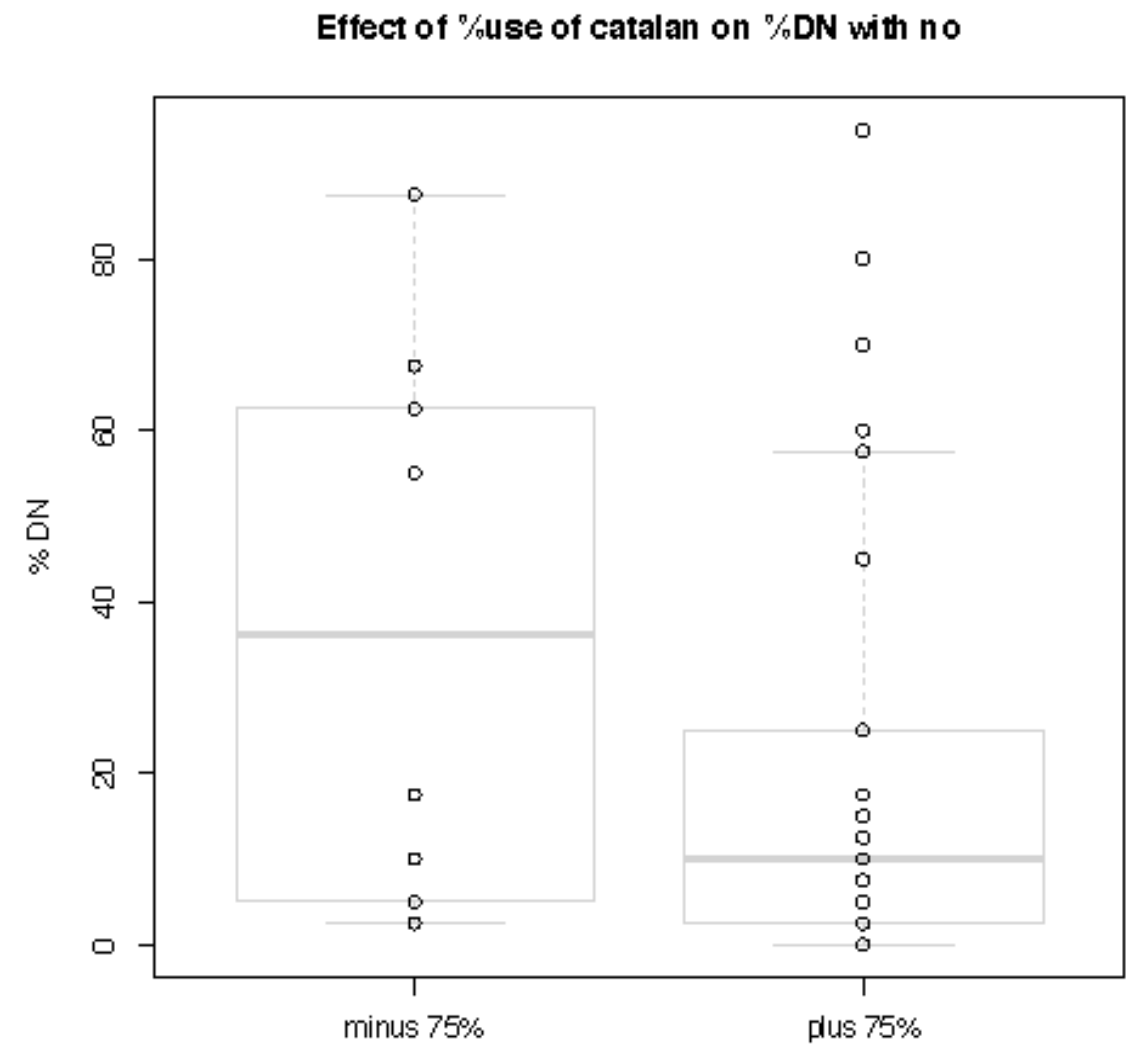

926

927

Figure 12. Effect of percentage of use of Catalan on DN choice in Experiment 2

928

(with $n o$ ) 


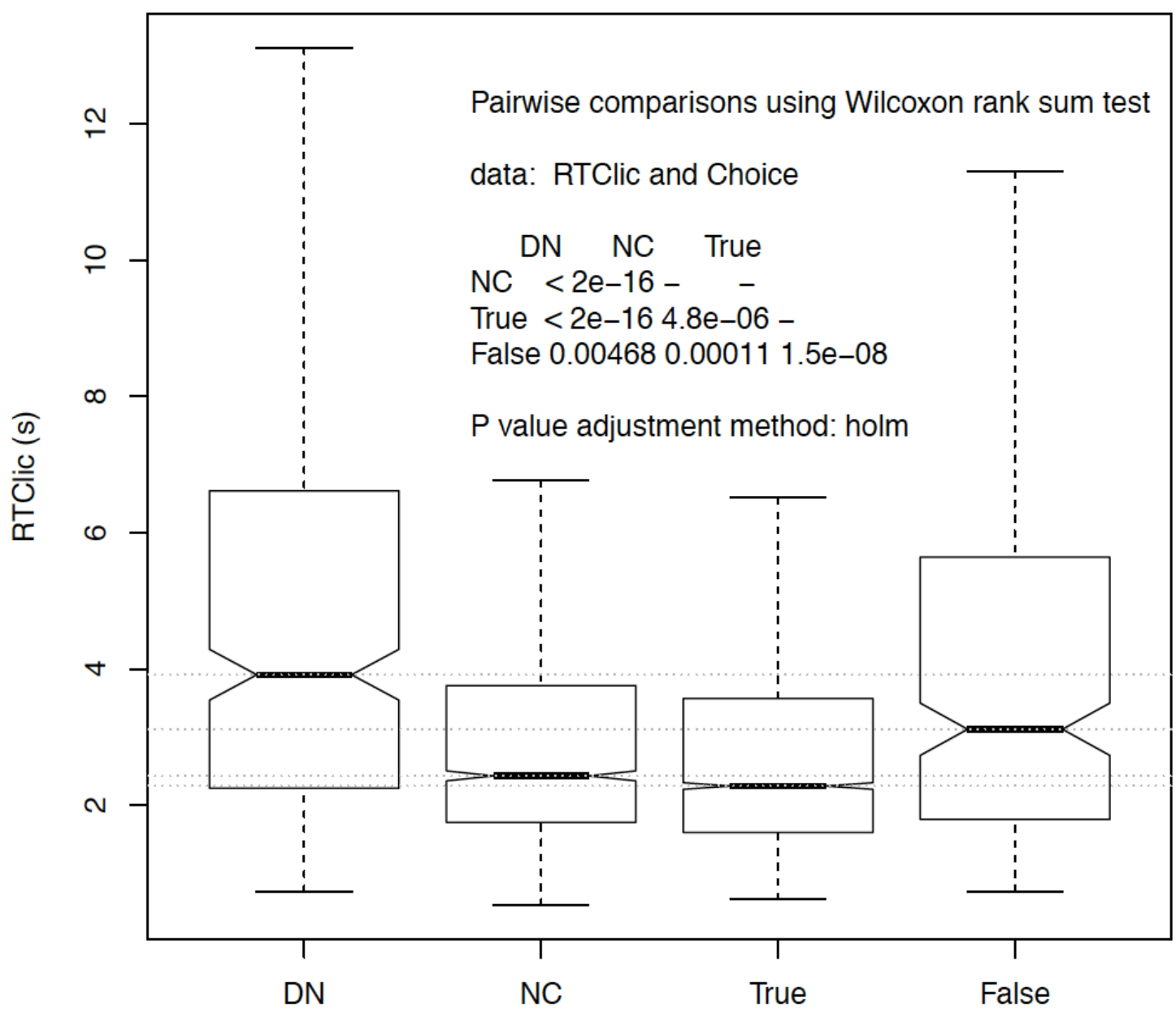

Figure 13. Reaction time (in seconds) between display of the images and the participants' click on the chosen image.

933 Wilcoxon rank sum tests with Holm correction revealed significant differences

934 between False vs. True responses in the control conditions $(p<0.001)$. True responses

935 were faster than False ones (on average, 3.13s for True and 4.95s for False). Significant

936 differences were also found between DN vs. NC / single negation responses in the critical

937 conditions $(\mathrm{p}<0.001)$. The Figure clearly indicates that $\mathrm{NC} /$ single negation responses are

938 processed faster than DN ones (on average, 3.41s for NC and 5.35s for DN). 


\section{5. Discussion}

941 In this section, we return to the four initial questions that our experiment was designed to

942 investigate concerning, first, whether, as standardly assumed by Catalan grammarians,

$943 \mathrm{NC}$ is systematically and consistently the default interpretation for sentences with

944 multiple NCIs; testing this possibility was important both to probe the nature of Catalan

945 NCIs with regards to whether or not they could be negative expressions, as de Swart

946 (2010), among many others, hypothesized, and to establish a baseline for further

947 manipulations. Our choice of a preference test was guided by an aspiration to find out not

948 only whether $\mathrm{NC}$ is indeed a default reading but also to what extent, if at all, DN readings

949 could arise as a possible interpretation of Catalan NCI sequences in monoclausal

950 transitive negative sentences. Second, to deepen this question, we further asked whether

951 NC could be easier to process than DN readings, as hypothesized by Corblin et al. (2006),

952 DN being quite generally assumed to be cross-linguistically more marked than NC (de

953 Swart 2010, Puskás 2012). Third, we explored whether the co-presence of the negative

954 marker no could influence the readings of NCI sequences and boost DN readings, as

955 predicted by Zeijlstra (2004) if Catalan has a variety with Non-Strict NC, such as Spanish

956 or Italian, but contrasting with the traditional description of Catalan. Finally, we sought to

957 examine whether the morpho-syntactic make-up of NCIs (DP vs. Pro) and their syntactic

958 position could influence the reading of Catalan negative sequences, favoring $\mathrm{NC}$ or DN

959 as was suggested to be the case for other NC languages (Italian, French) (Acquaviva

960 1995, 1997; Déprez 2000, 2011a, b). This question also aims at probing both the nature of

961 Catalan NCIs, surveying in particular whether their morpho-syntactic composition can 
962 affect the reading they trigger in a negative NCI sequence, and the nature and stability of

963 the Catalan concord dependency across a variety of negative expressions.

964 The section is organized as follows. We begin by summarizing the experimental

965 results that bear on the question of the default nature of Catalan $\mathrm{NC}$, and then turn to

966 consider what our processing results bring to this issue. We then move to considering the

967 DN boosting effects that the co-presence of no had on Catalan NCI sequences, assessing

968 how proposals in the literature fare in view of our experimental results. Finally, we turn

969 to the properties of NCIs that our results have revealed, the consideration of their effects

970 in influencing the interpretation of NCI sequences, and how these could be explained in

971 current theoretical approaches to NC.

972

973 5.1. NC as a default reading in Catalan

974 Turning to our first question on the default nature of NC readings, it is evident that first

975 and foremost, our results, with $84.56 \% \mathrm{NC}$ preferred choice in both experiments

976 confounded, bring conclusive experimental confirmation that $\mathrm{NC}$ is indeed

977 uncontroversially the prevalent interpretation in Catalan for negative sequences of all the

978 types considered here, namely monoclausal transitive sentences with NCIs in both pre-

979 verbal and post-verbal positions with and without no. In this respect, our experimental

980 findings, which fully accord with the abundant traditional and theoretical literature on

981 Catalan negative dependencies (see references in the Introduction), is evidently, not

982 novel. It is worth noting, however, that a fully comparable experimental protocol yielded

983 quite different results for another presumed uncontroversial NC language, namely

984 French, in which Déprez (2014) found no comparable NC prevalence. Thus, our Catalan 
985 results are not as trivial as it may appear, as they establish -for the first time, to our 986 knowledge- an experimental base line of how prevalent the choice of an NC 987 interpretation can be in an undisputable NC language, thus providing an informative basis 988 for further cross-linguistic comparison of NC vs. DN preference.

989 Just as clearly, but surely more surprisingly, our experimental results further show 990 that DN readings can in fact arise in simple transitive Catalan clauses, with a certain 991 amount of variability that depends essentially on two central factors: (i) the overt 992 presence of pre-verbal no 'not', shown to be massively significant in inducing possible 993 and preferred DN readings, and (ii) the complex vs. non-complex nature of NCIs and 994 their position, which also clearly influenced the availability of DN readings, though to a 995 lesser degree. We return to a more detailed discussion of the significance of each of these 996 factors and their combinations below.

997 Briefly, however, let us here comment on the rather surprising observation that DN 998 interpretation arose at all in simple Catalan monoclausal transitive sentences with two 999 NCIs, in the absence of sentential negation or any explicit favoring context (see Figure 6 1000 for Experiment 1). This possibility evidently raises the question of where the two 1001 conflicting semantic negations required for a DN reading could come from. Clearly, a

1002 first semantic negation must be triggered by the presence of an NCI in pre-verbal 1003 position, which, as is otherwise known, suffices to produce a negative sentence. The 1004 second semantic negation, however, could just as clearly, only come from the post-verbal 1005 NCI. As such, this appears to provide a first piece of evidence that Catalan NCIs cannot 1006 simply always be non-negative indefinites, as they must -at least sometimes- have the 1007 possibility of being semantically negative on their own or of triggering the presence of an 
1008 additional abstract negative operator. In Section 5.3 below, we further discuss how 1009 exactly such a DN reading can arise in the grammar of Catalan, as several possibilities 1010 are imaginable, including lexical variants (Herburger 2001), syntactic variants (Déprez 1011 2000), or a difference in feature composition (Martins 2000; Labelle and Espinal 2014; 1012 and Espinal and Tubau 2014, to appear). Here we wish only to underscore the mere 1013 existence of these DN readings in neutral contexts, as this possibility, unexpected in a 1014 language in which NC is clearly the default interpretation, is predicted to be excluded 1015 from the start by traditional and descriptive grammars of Catalan and under a strict 1016 macro-parametric approach to NC. But of course, it must be kept in mind that, if 1017 surprising, this observation only concerns a rather small proportion of responses in

1018 Experiment 1 (without $n o$ ), namely only 6.34\%, which although slightly larger than the 1019 overall proportion of errors in our most challenging control, the Negative Quantifier 1020 control $(5.10 \%)$, is not statistically significantly different. In this regard, although 1021 suggestive, this observation surely cannot constitute firm evidence that Catalan NCIs 1022 must be negative, as these DN readings could, in principle, mostly be due to errors. 1023 Below, however, additional evidence in support of this possibility is examined.

1024 To sum up, although our experimental results basically uphold the overall traditional 1025 picture of Catalan as a strongly NC language, they also paint a more nuanced picture that 1026 is not entirely compatible with the predictions of formal syntactic approaches casting NC 1027 as the direct consequence of a rigorous macro-parametric choice. In the upcoming 1028 sections, we focus our discussion on exploring possible explanations for why certain 1029 factors (i.e., the overt presence of pre-verbal no, the structural complexity and the 1030 distribution of negative expressions) should matter at all in eliciting DN interpretations in 
1031 Catalan, given that this language is primarily an uncontroversial NC language. We also

1032 focus on understanding what this reveals about the nature of Catalan negative

1033 dependencies. Before we turn to these points, however, we examine the impact of the

1034 processing results in our experiments, which revealed a significant difference between

$1035 \mathrm{NC}$ and DN.

1036

1037 5.2. Processing NC vs. DN

1038 As was shown in Figure 13 above, our experimental results demonstrate that Catalan

1039 speakers clearly required less time to choose a picture corresponding to a NC reading and

1040 more time to choose a picture corresponding to a DN one, in both Experiment 1 (without

1041 no) and Experiment 2 (with no) confounded. Moreover, in Experiment 1 the time to NC

1042 choice is essentially the same as the True choice for our control items, clearly suggesting

1043 that monoclausal transitive negative sentences are processed easily under an NC reading.

1044 Although the measure we recorded (time to picture choice) is not fully comparable to that

1045 of a more standard reading time, since it involves conscious choice rather than an

1046 unconscious reading speed, it nonetheless records a measure of reaction. In this regard,

1047 we conjecture that this measure can be revealing of the comprehension process that is

1048 taking place in the speaker's mind after reading the relevant sentence. Understood as

1049 such, the significant difference we found here in Catalan between NC and DN choice

1050 appears to provide strong support for Corblin's (1996) hypothesis that NC is easier to

1051 process than DN. This, along with the observation that languages featuring $\mathrm{NC}$ are

1052 usually more frequent in the world's cross-linguistic landscape (cf. Dryer and

1053 Haspelmath 2013) than those featuring DN, and with Bickerton's (1983) well-known 
1054 remark that $\mathrm{NC}$ is common to all creole languages, further appears to strengthen the

1055 already commonly held view that NC could be universally a more natural default reading

1056 for sequences of negative expressions than DN (de Swart 2010 among others). Should

1057 NC turn out to be easier to process than DN quite generally, then these cross-linguistic

1058 generalizations could perhaps even be rethought in processing terms.

1059 However, it must be kept in mind that surprisingly little is in fact known about the 1060 processing of either NC or DN constructions cross-linguistically. Furthermore, although

1061 simple negative sentences are quite generally thought to take longer to process than

1062 positive ones, recent work by Deutsch et al. (2009) shows, in contrast, that negation can

1063 be processed unintentionally and very quickly. Similarly, an analysis of negative

1064 dependencies in English using an experimental protocol similar to the one used in our

1065 study shows that in English, DN readings are in fact processed faster than NC ones and

1066 about as fast as control items (Déprez 2014). In addition, note that while Corblin's (1996)

1067 ease of $\mathrm{NC}$ processing conjecture was originally offered to explain $\mathrm{NC}$ preferences in

1068 French, it turns out that as Déprez (2014) shows also on the basis of experimental results

1069 obtained in conditions fully parallel to the ones discussed here, French, in fact, manifests

1070 no comparable speed advantage for NC over DN choices. That is, in French, contrary to

1071 Catalan, both DN and NC choices took essentially the same time, with no statistically

1072 significant difference between the two. Thus, ease of processing for NC seems in fact to

1073 be language relative, with possible cross-linguistic variation, and not a fully general

1074 characteristic of DN across languages.

1075 Furthermore, note that if ease of processing were a general NC processing 1076 characteristic, as conjectured by Corblin, the facts observed here, namely that DN 
1077 interpretations seem sensitive to the syntactic complexity of NCIs and to their syntactic 1078 position (DP vs. Pro in pre-verbal position) would be rather unexpected. The logic of

1079 Corblin's argument indeed should lead to the reverse expectation, at least considering 1080 complexity. To see that, consider a sequence of NCIs with a certain complexity. 1081 Assuming with Corblin (1996) that speakers choose an NC reading to ease its processing, 1082 it would be expected that if the sequence is made syntactically more complex, the 1083 pressure to pick a reading easier to process should increase. Our results, however, show 1084 the opposite tendency. Increased complexity in the NCI sequence, i.e., at least the 1085 presence of DP NCIs vs. the simpler Pro in pre-verbal position, favors an increase in DN 1086 readings, not NC. Hence, what both this language-internal observation and the cross1087 linguistic difference between French and Catalan NC processing suggest is that ease of 1088 processing may not be a factor that generally favors NC readings, but rather it could be 1089 the processing speed that depends on the choice of NC. If so, our processing results for 1090 Catalan here can be said to uphold Corblin's (1996) hypothesis, but with a twist, namely 1091 that ease of processing could be a consequence of a grammatical or semantic pressure for 1092 NC in Catalan, and not a motivation underlying the NC choice. Note furthermore, that if 1093 NC readings had different sources cross-linguistically, i.e., if they derived from distinct 1094 semantic processes such as variable binding (NPI licensing) or resumptive quantification 1095 in different languages or in different negative sentence types (Déprez 1997 and 1096 following), then it may well be that ease of processing could characterize some of the 1097 semantic processes that derive NC, but not others. Thus, for instance, if in French, but not 1098 in Catalan, NC results from resumptive quantification (Déprez 2000, de Swart and Sag 
1099 2002), then cross-linguistic variation and even language-internal variation in the

1100 processing ease of NC could be expected.

1101

1102 5.3. The role of no: are there two NC varieties for Catalan?

1103 In this section, we turn to what is perhaps both the most unexpected and the most

1104 interesting result of our experiments, namely the massive increase in DN readings that

1105 arose in NCI sequences in the co-presence of the sentential negation marker no. Although

1106 as noted above, DN readings are by and large statistically undistinguishable from errors

1107 on our controls in Experiment 1 (without no), this is not at all the case in Experiment 2

1108 (with no), where overall, a solid $24.29 \%$ of DN -highly significantly different from error

1109 rate on controls- is observed. It is, hence, clear that the increase in DN here is not due to

1110 error. In this section, we discuss possible explanations for this result, and their relation to

1111 the existence of two competing varieties for Catalan NC.

1112 Recall from Section 2.2 that in the linguistic literature, the optionality of no in

1113 Catalan has been related to the existence of two NC dialects (van der Wouden and Zwarts

1114 1993, Zeijlstra 2004). In these approaches, the optionality of no is taken to be essentially

1115 illusory as it results from the interaction of two distinct varieties, unclearly distributed in

1116 the population. According to Zeijlstra (2004), in the variety identified as Catalan I above,

1117 the presence of the sentential marker should be as obligatory as in Strict NC languages

1118 such as Greek, or Romanian, and have no effect on an unambiguous NC interpretation. In

1119 the variety identified as Catalan II, in contrast, the presence of the sentential marker

1120 should essentially be disallowed with pre-verbal NCIs, and when enforced, should lead to 
1121 an obligatory DN interpretation, as in Non-Strict NC languages such as Spanish or 1122 Italian.

1123 If we focus on our sentence data, it seems clear that the overall results of our

1124 Experiment 2 (with no) fail to support traditional Catalan descriptions, which basically

1125 suggest the existence of a single variety where -after pre-verbal NCIs- no is optional and

1126 makes no contribution to the sentential meaning. As our results show, there is little doubt

1127 that the presence of no significantly affected the interpretation of negative sentences, as

1128 indicated by the sharp increase of DN choice.

1129 However, if instead we focus on our subject data, we observe that the effect of no is

1130 unevenly distributed in our population. Going back to Figure 11, note first that there are

1131 at least some speakers (actually 4) for whom the co-presence of no with pre-verbal NCIs

1132 makes no difference at all. These subjects simply never chose a DN reading in any of our

1133 critical condition as well as in the NPI control, which as explained above, was parallel in

1134 this regard to our critical conditions in Experiment 2. To these subjects, one could add

1135 some more speakers that produce an amount of DN that essentially hovers around the

1136 amount of errors in our control items (see the Results section). But the exact number and

1137 cut is far from clear, as it partly depends on the control items taken as referent, and the

1138 leniency adopted for inclusion in this group. Nevertheless, what is of interest in Figure 11

1139 is that overall, we observe an essentially bimodal distribution of our subjects, with a

1140 larger group of 24 speakers choosing DN between $0-25 \%$ of the time, and a smaller group

1141 of 11 speakers choosing DN almost half of the time or more.

1142 These data may indeed suggest, as hypothesized by Zeijlstra (2004) among others, 1143 that there are two varieties of Catalan, one with a largely negligible amount of DN 
1144 readings and the other for which DN readings are clearly a possible option; for this

1145 second group of subjects, DN is chosen from $40 \%$ of the time up to almost all the time

1146 (90\%), depending on the subjects. As it turns out, however, neither of these two

1147 populations appears to pattern in complete accordance with Zeijlstra's predictions for

1148 Catalan. Recall from Experiment 1 (without no), that all speakers clearly interpreted NCI

1149 sequences without no massively as NC and that they made this choice as fast as that of

1150 correct responses to our controls. This strongly confirms the traditional grammar view

1151 that Catalan sentences with pre-verbal NCIs and without no are fully acceptable for all

1152 speakers. Hence, these data show unequivocally that there is no variety of Catalan

1153 equivalent to a Strict NC language where the co-presence of sentential negation is

1154 compulsory with pre-verbal NCIs. Thus, if there are indeed two varieties of Catalan, as

1155 seems likely in view of the bimodal distribution of subjects observed, the first variety is

1156 one in which no is optional and leaves the preferred NC interpretation essentially

1157 unaffected, exactly as described by traditional Catalan grammars.

1158 Note that for this variety, Zeijlstra's macro-parametric model is problematic. Recall

1159 that in his typology, Strict NC languages are characterized by a semantically non-

1160 negative ([uNeg]) sentential marker, and semantically non-negative ([uNeg]) NCIs. Yet,

1161 for Zeijlstra's model to correctly predict the obligatory co-occurrence between NCIs and

1162 the sentential negation marker in Strict NC languages, the latter must be the only element

1163 able to trigger/license the presence of an abstract [iNeg] operator, so that pre-verbal NCIs

1164 correctly fail to be able to license post-verbal ones. But this makes incorrect predictions

1165 for his Catalan Variety I. To account for the Catalan Variety I, in which no is optional

1166 and leaves the NC interpretation unaltered, there are essentially two possibilities. First, 
1167 Catalan Variety I could have pre-verbal NCIs that are semantically negative (or

1168 equivalently, trigger an abstract negative operator) and a sentential negation marker that

1169 is semantically non-negative, i.e., an expletive negation. Recall from the Introduction that

1170 Espinal (2007) and Espinal and Tubau (to appear) argue that such a marker is

1171 independently needed in Catalan to account for the phenomenon of expletive negation

1172 and is essentially a strong NPI-like element. Second, pre-verbal NCIs in the Catalan

1173 Variety I could be ambiguous between semantically negative expressions able to occur

1174 alone in pre-verbal positions, and polar NCIs, requiring the co-presence of negation even

1175 when in pre-verbal subject position (i.e., a special kind of NPI expressions equivalent to,

1176 for instance, the Hindi NPI expressions in Lahiri's 1998 work). On this alternative view,

1177 positing an expletive negation is not needed, but it must be assumed that the Catalan

1178 polar NCIs can be licensed in pre-verbal positions by a negation that may fail to strictly

1179 c-command them, at least in their Spell-Out position. Several proposals along these lines

1180 have been developed, offering distinct accounts on what licenses these NPI-like

1181 expressions pre-verbally (Martins 2000; Déprez 2000, to appear; among others). ${ }^{13} \mathrm{We}$

1182 return to such a proposal in section 5.3 where we discuss the nature of Catalan NCIs.

1183 The second variety that Figure 11 revealed is one in which the presence of no

1184 significantly increases DN readings, but, in which, crucially, DN readings are not

\footnotetext{
${ }^{13}$ Recall that for Martins (2000) a distinction is made between weak NPIs and strong NPIs. In order to account for the Catalan facts she must assume the following: if no is explicit, a weak NPI must have been selected, whereas if no is not overt, a strong NPI must have been selected. What exactly enforces this choice remains to be clarified.

In relation to this issue a reviewer raises the question of what the difference is between assuming that $n o$ is an expletive and assuming that no is a standard negative marker that does not necessarily undergo phonological realization. The semantic markedness of negation in natural languages seems quite indisputable, and so does the fact that the non-affirmative nature of the meaning (input) is reflected in the linguistic form of the output (cf. Faithfulness to negation, Hendricks et al. 2010). This notwithstanding, the semantic content of a negative marker has been argued to be submitted to a process of logical absorption when certain logical and structural conditions are met (Espinal 1992, 2000b).
} 
1185 obligatory, since NC remains overall the favored interpretation for negative sequences, 1186 even in Experiment 2 (with no). Here Zeijlstra's (2004) macro-parametric model also

1187 encounters difficulties. In this model, the presence of pre-verbal no, assumed to be

1188 always semantically negative in Non-Strict NC languages such as Spanish and Italian, is

1189 predicted to always yield DN. Given that Zeijlstra's Catalan II is described as Non-Strict,

1190 the existence of a group of speakers for whom DN is the only choice for pre-verbal NCIs

1191 followed by no is expected, but this is not what we found. For this second variety, we

1192 thus have to conclude that either a non-negative no is also part of this variety, but need

1193 not be used whenever it is licensed, or, alternatively, that pre-verbal polar NCI licensing

1194 by a non-c-commanding negation has become more costly.

1195 Assuming that Catalan has two lexically distinct (but homophonous) sentential 1196 negative markers $n o_{1}$ and $n o_{2}$ as proposed in (20) (Espinal and Tubau to appear), and two

1197 lexical variants of NCIs: $N C I_{1}$, which is a polar variant that can trigger an abstract 1198 negative operator, and $\mathrm{NCI}_{2}$, a negative existential quantifier, as proposed in (21) (Espinal 1199 and Tubau 2014), the distinction between the two varieties we observed can be accounted 1200 for as follows. In Variety A, whenever no is present, speakers automatically use the 1201 expletive form whenever it is locally c-commanded by a non-veridical licensing element.

1202 This correctly predicts that only the expletive form can be used with pre-verbal NCIs, but 1203 not with post-verbal ones, since in this case, the expletive no would itself not be 1204 appropriately licensed. This variety appears to be characterized by a constraint that 1205 requires that only the highest potentially negative element in a chain be associated with 1206 an actual semantic negation, either overtly or covertly (characterized [iNeg]), and 1207 precludes all the following potentially negative elements in a chain to be semantically 
1208 negative ones. This is a form of Neg-first constraint, though distinct from the one

1209 proposed by de Swart $(2010)^{14}$, since it concerns negative interpretation, rather than

1210 morpho-syntactic marking. For some of these speakers, we suggest that the residual small

1211 amount of DN found could presumably arise from errors or from the interaction of two

1212 (possibly negative) NCIs, as seen in Experiment 1 (without no) (see Figure 6), but not

1213 from the presence of no.

1214 In Variety B, in contrast, the use of the expletive form of the negator is not enforced

1215 under c-command by an [iNeg] element. Speakers instead may use freely either the

1216 semantically negative sentential marker or the expletive one, with a lot of intra-speaker

1217 variability, and with the latter option being regressive and becoming less and less

1218 common. ${ }^{15}$ This accounts for the fact that the massive DN-triggering-no-effect observed

1219 is largely driven by this smaller group. However, here as well, Zeijlstra's Catalan II is not

1220 strictly realized, although it seems apparent that some speakers are transitioning to it.

1221 Note that these observations provide support for the view defended in Section 2.2 that

1222 contemporary Catalan has two different lexical entries for no, one $n o_{1}$ which is

1223 semantically negative, and one $n o_{2}$ which is semantically non-negative, i.e., expletive.

1224 Recall that in this regard, Catalan appears similar to Afrikaans, for which Biberauer

1225 (2013) similarly recently concluded that a strong macro-parametric model such as the one

1226 proposed by Zeijlstra (2004, and subsequent work) made incorrect predictions.

\footnotetext{
${ }^{14}$ Recall that this Optimality Theory constraint specifies that "Negation precedes the finite verb" (de Swart 2010: 96).

${ }^{15}$ It is interesting to note that in this respect, Catalan is also rather similar to Québec French in which both negative markers, ne and pas can participate in NC constructions. Strikingly, however, as observed by Daoust-Blais (1975), Muller (1991), Di Sciullo and Tremblay (1996), and Déprez and Martineau (2004), among many others, only ne can surface in sentences with pre-verbal NCIs, while pas is excluded or leads to DN readings. In recent work, Burnett and Tremblay (2014) show additionally that there is much variation in the co-occurence of pas with distinct types of NCIs. The subject variability that we observe here in Catalan with respect to the effect of no does clearly not seem to be unique to this language.
} 
1229 class of speakers that use Catalan more than $75 \%$ of the time in their daily lives, as the

1230 following table reveals.

\begin{tabular}{|l|c|c|}
\hline \multicolumn{1}{|c|}{ Percentage of subjects } & minus 75\% Catalan & plus 75\% Catalan \\
\hline$\% \mathrm{DN}>25 \%$ & $14.28 \%$ & $17.14 \%$ \\
\hline$\% \mathrm{DN} \leq 25 \%$ & $14.28 \%$ & $54.28 \%$ \\
\hline
\end{tabular}

Table 4. Correlation between percentage of DN readings and percentage of use of

1233 Observe that $54.28 \%$ of our subjects use Catalan more than $75 \%$ of the time in their 1234 daily lives and have less than $25 \%$ of DN. These are the subjects closest to what 1235 traditional grammars describe. But the cut is not as sharp as one could wish, since in this 1236 category of $75 \%$-of-Catalan users, there are still $17.14 \%$ who chose DN between $40 \%$ to $123790 \%$ of the time. To confirm the tendency here observed, a follow-up study that would 1238 properly balance the sampled population for age, use of Catalan in daily life, region and 1239 socio-economic factors would be needed. If confirmed, this would demonstrate that the 1240 Catalan speakers that deviate from the model described by traditional grammars are 1241 speakers that may be more under the influence of their second native language, namely 1242 Spanish, a textbook characteristic Non-Strict NC language. ${ }^{16}$

\footnotetext{
${ }^{16}$ As pointed out by one reviewer, this discussion raises the following interesting cross-linguistic query: do Strict NC languages tend to allow more EN than Non-Strict NC languages? We observe that, as a NonStrict NC language, Spanish clearly manifests a reduced use of EN as compared to Catalan (see footnote 6, above). Thus concerning Catalan Variety B (see Table 3), we do not predict full absence of EN from all contexts that usually allow it, but, crucially, diminished frequency of use as compared to the Catalan Variety A (with EN perhaps lacking altogether for only some speakers). We further observe here that along with our predictions, Greek and Romanian, two Strict NC languages, manifest an extensive use of EN in
} 
1244 is one that only partially fits the predictions of either the traditional view of Catalan or of

1245 Zeijlstra's proposed model. With respect to the use of no, we conclude that no is optional

1246 in all varieties of Catalan and there is no variety in which it is either systematically

1247 required, or systematically rejected. Yet, with respect to the existence of two NC

1248 varieties, our data indeed suggest that they are attested, and we suggest that whereas for

1249 one population an expletive no most often (optionally) co-occurs with pre-verbal NCIs, in

1250 another population this is a regressive option and both the negative and the expletive

1251 variants are variably allowed. Hence, the presence of no is increasingly associated with

1252 DN readings, as it is interpreted as semantically negative to a varying extent.

\section{5.4. The nature of Catalan NCIs}

1255 While it is clear that the most important factor triggering potential DN readings in

1256 Catalan is the co-presence of no with NCIs, Experiment 2 (with no) also provided strong

1257 evidence that the differing morpho-syntactic nature of NCIs matters in influencing the

1258 interpretation of negative sentences and fostering DN readings. In particular, our results

1259 showed that complex NCIs, i.e., DPs with full NP complements, or partitive DPs, in

1260 contrast to simple Pronominal NCIs, have the effect of significantly raising the number of

1261 DN choices that speakers made, particularly when they occur in pre-verbal positions.

1262 Concerning the types of negative sequences we tested, we observed specifically that in

the canonical EN contexts. However, more thorough verification of the correlation put forward in this paper between the occurrence of a negative marker with pre-verbal NCIs and the extensive use of EN beyond NC contexts must remain a topic of future research. We would like to thank Elena Ciutescu and Ana Maria Falaus for informing about Romanian, and Artemis Alexiadou, Anastasia Giannakidou, Dimitra Lazaridou and Melita Stavrou for informing about Greek. See also Pană Dindelegan (2013) for Romanian, and Makri (2013) for EN beyond Romance. 
1263 Experiment 2 (with no), our Control NPI sequences most increased the choice for DN,

1264 followed by DP DP sequences, DP Pro sequences, Pro Pro and finally Pro DP sequences

1265 (cf. Figure 7). ${ }^{17}$ In this section, we examine how these results bear on what has always

1266 been a core question about NC, namely the nature of the dependent negative items that

1267 participate in it.

1268 Before we turn to a more detailed account of the specific influence of NCI types on

1269 DN vs. NC choice, it is worth stressing here that the mere existence of such effects is

1270 unpredicted under a macro-parametric approach to NC. Clearly, a macro-parameter that

1271 regulates whether or not a language has a formal negative feature $[+/-\mathrm{u} / \mathrm{iNeg}]$ has

1272 nothing to say about why certain types of NCIs can induce more DN / NC readings than

1273 others within the same language. A proper account of how the nature of NCIs can

1274 differently affect $\mathrm{NC} / \mathrm{DN}$ choice requires attention to the internal micro-parametric

1275 make-up of the NCIs themselves and not just to the general nature of the dependency, as

1276 strongly advocated in Déprez's works (1997-2011). These type of data, then, demonstrate

1277 that languages are not homogeneously of NC or DN types, as expected under a macro-

1278 parametric approach, but feature, rather, NC inducing vs. DN inducing negative

1279 structures and expressions that can be similar or not across languages and that can differ

1280 or not language-internally. Thus the variation in interpretation, uncovered here, that is

1281 induced by diverse NCI types within a single language provides an important

\footnotetext{
${ }^{17}$ A reviewer noted that for him/her and other Italian speakers, sequences of NCIs with full DPs predominantly give rise to $\mathrm{DN}$ readings, in apparent contrast to our Catalan data, and asks why this should be so. In this regard, we first point out that in our Experiment 2 (with no) Critical DP DP gave rise to $28.21 \%$ of DN, higher than other NCI sequences (cf. Pro Pro in contrast). The trend does thus not seem to be absent for Catalan. Yet, before comparative conclusions could be drawn with regards to such NCI sequences in other Romance languages, it seems important to experimentally verify native speakers' interpretations, as judgements for DN readings are notoriously unstable, and the discussion of such facts in the literature is rather thin. At this point, we note that in comparable experimental settings, Déprez (2014) observed a similar increase in DN rate for French. The Italian data are also currently in the process of being investigated with the same experimental protocol.
} 
1282 experimental confirmation for a micro-parametric inside out approach to variation in NC,

1283 historical, cross-linguistic or language-internal (Déprez 2000, 2011b, 2014; Déprez and

1284 Martineau 2004; Labelle and Espinal 2014).

1285 Returning to the question of NCI types, recall that, by and large, four families of 1286 approaches to the nature of NCIs have been commonly distinguished in the literature. The

1287 first one considers NCIs as non-negative indefinite expressions that depend on negation 1288 (or non-veridical operators) to be licensed (Ladusaw 1992, 1994; Zeijlstra 2004; Penka

1289 2011; among others); in the second one NCIs are always negative quantifiers (Zanuttini

1290 1991, Haegeman and Zanuttini 1991, de Swart and Sag 2002, among others) and NC

1291 obtains through resumptive quantification; in the third one, NCIs are wide scope

1292 universals that outscope their licensing negation (Giannakidou 2000); and in the fourth

1293 one, NCIs are ambiguous between the first and second type (Herburger 2001). On the

1294 first and third views, NCIs are essentially dependent polar expressions that require 1295 specific contexts to be licensed. For Catalan, recall from our Introduction that in Espinal

1296 and Tubau's (2014, to appear) model, the polar variety of NCIs is characterized with a

1297 semantic strong $[+\sigma]$ feature, following Chierchia's (2006) characterization of NPIs, and

1298 with a morpho-syntactic [uNeg] feature. However, Catalan NCIs cannot just be of this

1299 type, lest the DN readings that we see arising in both Experiment 1 (without no) and

1300 Experiment 2 (with no) would remain unaccounted for. ${ }^{18}$ NPIs indeed, even of the

1301 strongest type, never lead to DN readings, even in denial contexts (otherwise known to

\footnotetext{
${ }^{18}$ Puskás (2012) provides an interesting account of why DN could arise in a symmetric NC language like Hungarian under particular contextual circumstances. It is however unclear how her proposal could transpose to the cases under considerations here, particularly for Experiment 1 (without no) since there is no sentential negation involved. Moreover, even for Experiment 2 (with no), the sentences here considered are not embedded in the contexts that Puskás assumes to be necessary for a DN interpretation to arise in Hungarian.
} 
1302 favor the felicity of such readings). To allow for DN readings to arise at all outside of any

1303 particular facilitating contexts (cf. Experiment 1), it must be assumed that Catalan NCIs

1304 can also either systematically trigger the appearance of their own abstract negative

1305 operator, or have the ability to be semantically negative by themselves. In other words,

1306 our results support the view that Catalan NCIs must be ambiguous, allowing both for a

1307 non-negative polar-like variant in sentences with an $\mathrm{NC}$ interpretation and for a

1308 semantically negative one to allow DN readings (cf. (21) in the Introduction section).

1309 The idea that NCIs are ambiguous is of course not new, as it has been repeatedly

1310 proposed in different versions at different times. Among the first to argue for such an

1311 ambiguity was Longobardi (1987), but perhaps the best known defense of this type of

1312 analysis is that of Herburger (2001), who argued that Spanish NCIs are lexically

1313 ambiguous between a negative and a non-negative type, and that of Martins (2000), who

1314 argued for a typology of polarity items in Romance based on the well-established

1315 weak/strong distinction. Déprez (1997a, b, 1999, 2000) and Déprez and Martineau (2004)

1316 offer yet another ambiguity proposal, arguing that NCIs can be morpho-syntactically

1317 ambiguous, with each interpretation corresponding to a different internal morpho-

1318 syntactic structure. In these studies, it is proposed that NCIs with negative force occupy a

1319 high position in their nominal structure, while those that are non-negative indefinites

1320 occupy a low DP internal position. Recently, Déprez (2011b) argued that semantically

1321 negative NCIs occupy a (contrastive) topic/focus position within their internal DP

1322 structure (see for instance Ticio 2005 among others for such a position in the DP) that can

1323 either be derived via a DP-internal displacement (Kayne 2005) or be grammaticalized as

1324 a result of historical evolution. Schematically, the morpho-syntactic distinction can be 
represented as follows:

1326 (26) negative NCI : [Top/Foc NCI [DP ... [NumP [NP $]]]]$ non-negative NCI : $[$ Top/Foc $\quad[$ DP .... $[$ NumP $\quad[\mathrm{NP}$ NCI $]]]]$

1328 Assuming DP to be a phase (Chomsky 2000), Déprez (2011b) proposes that the 1329 negative feature of NCIs can become accessible at the sentence level (i.e., at a higher 1330 phase level of computation) and hence semantically interpretable only if NCIs occupy the 1331 edge of their constituent, i.e., here the highest structural position in the DP in these cases. 1332 Otherwise, when buried deep inside the DP constituent, the negative feature remains 1333 uninterpretable at the sentence level, so that NCIs are interpreted as non-negative. ${ }^{19}$

1334 Yet another proposal for NCI ambiguity is offered in Labelle and Espinal (2014) and

1335 Espinal and Tubau (2014, to appear). These authors argue that NCIs can have a different 1336 feature make-up, and that it is their distinct feature composition that is responsible for 1337 their differing interpretation. One lexical variant is a polarity item (defined as $[+\sigma]$ 1338 following Chierchia (2006)), which may acquire a syntactic formal feature [uNeg] in 1339 syntax that requires an Agree dependency to be established with an [iNeg] constituent; 1340 the other is a lexical variant that is a negative existential quantifier $(\neg \exists)$ endowed with an 1341 uninterpretable Focus feature, [uFoc]. Such a proposal is in line with Déprez's (2011b) 1342 proposal that negative NCIs that are semantically negative occupy a Focus position 1343 within their DP structure.

1344 Arguing for a choice among these alternative proposals for the ambiguity of Catalan 1345 NCIs lies beyond the scope of this particular paper. Of relevance to our purpose here is 1346 the idea that, in Catalan, the NCIs, as well as perhaps the sentential negative marker no,

\footnotetext{
${ }^{19}$ For an earlier formulation of this Feature Accessible Condition and it applicability to domains other than negation, see Déprez (1998, 2007).
} 
1347 can have distinct variants that compete within the same language. Let us now turn to

1348 consider what possibilities these assumptions offer in regards to our experimental

1349 findings.

1350 In comparison with Zeijlstra's (2004) macro-parametric view, the micro-parametric

1351 approach here advocated, which takes into account the possible ambiguous make-up of

1352 the Catalan negative marker, and of the Catalan NCIs, clearly offers more flexibility. It

1353 predicts that Catalan should allow for at least the following possibilities. The combination

1354 of a semantically negative sentential marker with NCIs that are semantically non-negative

1355 evidently leads an NC reading, which is comparable to the reading obtained in polarity

1356 dependencies. As we have seen, this is clearly a possibility in Catalan, and, perhaps, the

1357 most common one featuring a dependency between a sentential negation and a post-

1358 verbal NCI. To obtain this combination, we suggest that the semantically negative

1359 version of the sentential negative marker is its default interpretation, shared by all

1360 speakers of Catalan, in all variants. For NCIs, in contrast, we take the non-negative

1361 variant to be the default one. Concerning the two Catalan variants discussed above, we

1362 suggest that speakers of Variety A use the expletive $n_{2}$ when the optional negation is c-

1363 commanded by a negative NCI. Moreover, they only allow pre-verbal NCIs to trigger an

1364 abstract negative operator. ${ }^{20}$ This allows for the optionality of no without affecting the

1365 preferred NC reading of the sequences. Post-verbal NCIs, in turn, are licensed either like

1366 pre-verbal ones (by an abstract negative operator triggered by a pre-verbal NCI), or by

1367 negation.

1368 Let us now turn to consider the variety in which DN readings are clearly a 1369 possibility. Here we suggest that DN readings emerge from the combination of a negative

\footnotetext{
${ }^{20}$ We discuss below where this restriction may come from.
} 
1370 NCI in pre-verbal position and the semantically negative sentential negation marker, 1371 accounting for the massive effect of no that our data have uncovered. Additionally, we

1372 conjecture that for the same type of speakers, the possibility of DN readings in NCI

1373 combinations without no is also allowed to emerge from the possibility of having

1374 negative existential quantifier NCIs both in pre-verbal and in post-verbal positions.

1375 Evidently, this second possibility also arises in the presence of no, and also leads to a DN

1376 reading. For all varieties, additionally, the presence of either a negative NCI in pre-verbal

1377 position or a negative sentential negation marker and non-negative NCIs in post-verbal

1378 position leads to the preferred NC reading that is observed overall.

1379 Table 3, repeated here as Table 5 for convenience, summarizes the options our

1380 proposal has made available. A question that remains to be answered at this point is:

1381 when are these variants allowed or fostered?

\begin{tabular}{|l|c|c|}
\hline Catalan & NCIs in negative contexts & Negative marker(s) \\
\hline Variety A & $1 .[+\sigma]$ & $1 .[\mathrm{iNeg}]$ \\
& $2 . \neg \exists,[\mathrm{uFoc}]($ emergent) & $2 .[+\sigma]$ \\
\hline Variety B & $1 .[+\sigma]$ & $1 .[\mathrm{iNeg}]$ \\
& $2 . \neg \exists,[\mathrm{uFoc}]$ & $2 .[+\sigma]$ (regressive) \\
\hline
\end{tabular}

Table 5. Lexical variation in NCIs and the negative marker in Catalan

1383 Concerning the non-negative negation marker, it has been hypothesized in Espinal

1384 (2007) and Espinal and Tubau (2014, to appear) that speakers that have this variant of no

1385 also use it in so-called expletive negation constructions. This makes the clear prediction

1386 that speakers who chose a NC reading in sentences that combine two NCIs with the

1387 sentential negative marker no (Variety A) are also the ones who will otherwise manifest a

1388 relatively frequent use of expletive negation in the relevant constructions. Vice versa,

1389 speakers who chose a DN reading for these negative sequences (Variety B) will also lack

1390 or tend to reject expletive negative constructions. We aim to conduct further experimental 
work to verify this prediction.

1392 Note, however, that the two Catalan varieties uncovered in our results can also 1393 receive an alternative account that would locate their difference solely in the variable 1394 nature of their NCIs, thus possibly doing away with the contribution of an expletive 1395 negation. ${ }^{21}$ Relying on suggestions made in Déprez (to appear), such an account would go 1396 as follows. Recall that, descriptively, Catalan Variety A is a variety in which the 1397 sentential negation no optionally co-occurs with pre-verbal NCIs without affecting the 1398 NC interpretation. This can obtain, as discussed above, if the negative force is located in 1399 or triggered by the pre-verbal NCI and absent from the sentential negation, which is then 1400 an expletive negative dependent item. Alternatively, however, it can also logically obtain 1401 if the negative force is located in the sentential negation marker only, being then absent 1402 from the pre-verbal subject NCI. This option, however, is rarely explored in the literature, 1403 in view of the well-known fact that English-type NPIs require c-command by negation in 1404 their Spell-Out position. In turn, this type of c-command requirement, whose effect is to 1405 exclude English NPIs from pre-verbal subject positions, is commonly thought to 1406 generalize to all NPI expressions. Suppose, however, that there existed a type of negative 1407 dependent expressions for which this requirement could be relaxed. That is, suppose that 1408 for these Catalan preverbal items, c-command by negation of one of their copies -not 1409 necessarily the final Spell-Out one- could be sufficient for licensing. Given the so-called $1410 v$ P-Internal Subject Hypothesis (Koopman and Sportiche 1991), whereby pre-verbal 1411 subjects are derived by movement from a $v \mathrm{P}$-internal position, such relaxed negative

\footnotetext{
${ }^{21}$ Such an account is also suggested in Martins (2000), who proposes a feature specification for Catalan NCIs distinct from their Spanish and Italian counterparts in a feature underspecification system adapted from Rooryck (1994).
} 
1412 dependent expressions could occur in pre-verbal subject positions as long as overt

1413 negation c-commanded their $v \mathrm{P}$-internal copy. (27) illustrates this proposal:

1414 (27) [тр NCI [NegP no [T, [т [

1415

1416

1417

1418 First, assuming ambiguous NCIs that either lack or have negative force, pre-verbal NCIs

1419 lacking negative force would require the co-presence of sentential negation to be

1420 licensed, but with this licensing allowed in their base position (i.e., Spec, $v \mathrm{P}$ for subjects

1421 or VP for objects) under a single negation reading. By contrast, the NCI with negative

1422 force would occur pre-verbally, without no, and, in turn, license dependent post-verbal

1423 NCIs. In Variety A, the presence of no would trigger the choice of the negative dependent

1424 expression lacking negative force both in subject and object position.

1425 Variety B would then differ from Variety A as follows: in Variety B, pre-verbal

1426 NCIs that lack negative force would come to disallow licensing by negation in their base

1427 position, turning into English-like NPIs that require c-command by negation in their overt

1428 derived position. That is, option (27) becomes regressive. As a consequence, gradually,

1429 only NCIs with negative force are allowed in pre-verbal position, with the co-occurrence

1430 with no then leading to increasing DN readings. In post-verbal position, however, NCIs

1431 that lack negative force are still properly licensed by a c-commanding negation,

1432 accounting for the growing subject-object asymmetry. On this view, as well, since the

1433 distinction in Variety B leads to a closer resemblance to the asymmetric Spanish / Italian

1434 NC type, the tendency to regard speakers of Variety B as more sensitive to the influence

1435 of Spanish remains. 
Let us finally concern ourselves with the availability of DN readings with the

1437 negative variant of NCIs. Here several possibilities can be entertained, which ultimately

1438 depend on what the exact source of NCI ambiguity turns out to be. One interesting point

1439 deserves further attention. Recall that our data showed that the complexity of DP

1440 structure matters in fostering DN readings. As it turns out, most of the complex DP in our

1441 experimental material and particularly those in pre-verbal positions were partitive DPs

1442 (like for instance cap dels alumnes 'none of the students'). In recent work on Catalan

1443 partitive DPs, Martí i Girbau (1999) argued that these complex DPs involve DP-internal

1444 movement (predicate inversion) to a high position in the DP structure, as shown in (28):

1445 (28)a. molts dels llibres

1446 many of.the $\mathrm{PL}_{\mathrm{PL}}$ books

1447 'many of the books'

1448 b. [DP molts $\left[\mathrm{D} / \mathrm{PP}^{\mathrm{D}}\left[\mathrm{D} / \mathrm{P}^{\circ}\right.\right.$ de $\left[\mathrm{DP}\right.$ els [FP[NP llibres [Fo $\left.\left.\left.\left.\left.\left.\left[\mathrm{XP} \mathrm{t}_{\mathrm{i}}\right]\right]\right]\right]\right]\right]\right]$

1449 When associated with Déprez's structural proposal on NCI ambiguity, which relates

1450 the strength of the negative force of NCIs to a high position in DP structure, Martí i

1451 Girbau's (1999) structure for partitives suggests an interesting explanation for the

1452 increase in DN readings observed in our experimental results with full DPs that are

1453 mostly partitive NCIs. ${ }^{22}$ The significant increase in DN reading observed with partitives

1454 provides strong support for the proposal that the internal structure of NCIs matters for

1455 their interpretation and more specifically, that their negative force correlates with the high

${ }^{22}$ Sleeman and Kester (2002) propose an alternative analysis of partitive constructions in French without DP-internal predicate inversion. They argue for a clausal analysis in which the numeral/quantitative part of the partitive occupies a high position in the DP as in (i):

(i) deux pro $\left[\mathrm{FP}_{\mathrm{i}} \mathrm{F}^{\circ}\left[\mathrm{PP}_{\mathrm{i}}\right.\right.$ de $\mathrm{P}^{\circ}$ ses amis $\left.]\right]$

two of his friends

Given the similarity between numerals and NCIs proposed in Déprez $(1997,2000)$ and Espinal (2000), such an analysis naturally extends to partitive NCIs. 
1456 position of NCIs within their structure (Déprez 1997a, b, 1999, 2000, 2011b; Déprez and 1457 Martineau 2004).

1458 Note, furthermore, that, as is rather well known, subject DPs are far more often 1459 topics than object DPs (Prince 1992). If sentential DP topics are also DPs in which a DP 1460 internal (contrastive) topic/focus movement is fostered, this again hints at a plausible 1461 avenue to explain why DN readings should be particularly favored by complex DPs in 1462 pre-verbal subject positions. That is, the idea here is that the DN reading is fostered under 1463 a kind of structural parallelism between a DP occurring in a higher sentential edge 1464 position (topic/focus in Rizzi's 1997 sentential structure) and NCIs occurring in their

1465 higher edge DP-internal position, the edge position in both serving to enhance the 1466 visibility / interpretability of the negative feature in the sentential domain. Here too, 1467 further experimental verification that targets partitive NCIs and topic structure/focus 1468 structure within the DP and in the larger sentential domain is called for to solidify these 1469 novel conjectures.

1470 But independently of these particular conjectures, it is clear that what our current 1471 experiment results have shown is that the internal structure of NCIs matters for the 1472 overall interpretation of negative sentences. Note that this is exactly what a micro1473 parametric approach such as the one advocated in independent work (Déprez and 1474 Martineau 2004; Déprez 2011b; Espinal and Tubau to appear, 2014) predicts. We 1475 therefore conclude that the complex empirical landscape of the distribution of DN and 1476 NC interpretation that our experiment has uncovered provides solid support for a micro1477 parametric approach to NC. Such an approach takes into account possible lexical variants 1478 in the interpretation of the sentential negation marker but especially in the structure and 
1479 interpretation of NCIs, which can vary and compete within a single language.

\section{6. Conclusion}

1482 To conclude, this paper has presented experimental work that explored the interpretation

1483 of NCI sequences in Catalan with and without the co-occurrence of the negative marker

1484 no. Our results have shown that the empirical landscape of these constructions is far more

1485 complex than standardly assumed in the literature. Clearly, and unsurprisingly, our results

1486 have first and foremost confirmed experimentally that NC readings are overall the

1487 favoured reading of NCIs sequences in Catalan, both with and without the co-presence of

1488 the negative marker no, hence establishing an experimental base line useful for further

1489 cross-linguistic experimental investigation of NC constructions. But beyond this

1490 empirical confirmation, our results have also shown that in contrast to the traditional

1491 description of Catalan, the co-presence of the negative marker no with pre-verbal NCIs

1492 clearly affects the interpretation of NCI sequences as it can sometimes elicit DN readings

1493 in simple sentences outside of any particular favouring contexts. Interestingly, however,

1494 such DN readings are not elicited for all our subjects. As hypothesized by Zeijlstra

1495 (2004), the existence of two variants of Catalan that co-exist in the native speaker

1496 population seems to be supported by the near bimodal distribution of DN readings we

1497 observed in our sample population. The two variants, however, did not entirely pattern as

1498 predicted under Zeijsltra's model, as Catalan clearly does not feature a variant with Strict

1499 NC, but only a variant in which the co-presence of the negative marker is indeed optional,

1500 as described by traditional Catalan grammars. For the second variant, DN readings, which

1501 are generally not obligatory, are mostly elicited by the co-presence of no but were also 
1502 shown to increase with the particular structure of NCIs, and more specifically for 1503 complex DP NCIs such as partitive NCIs in pre-verbal position. To account for these 1504 facts, we argued for a micro-parametric approach to Catalan NC that features both a

1505 possibly ambiguous negative marker -semantically negative or expletive, the latter option

1506 being readily available for the speakers of Variety A, and regressive for the speakers of

1507 Variety B-, and ambiguous NCIs, non-negative and negative, variably available for all 1508 Catalan speakers. Alternatively, the option of licensing polar NCIs under c-command by 1509 negation of their base-merged copy, while solid in Variety A, would become regressive in

1510 Variety B, leading to a gradual ban for polar NCIs to occur in pre-verbal position. The

1511 paper further offers conjectures as to why certain types of NCI structures (complex or 1512 partitive DPs) can foster an increase in DN interpretation and why the pre-verbal position 1513 also matters. Overall, one of the central points of our experimental work is the 1514 demonstration of how crucial taking into account the elicitation of possible DN readings 1515 can be, for a better understanding of the nature of negative constructions in Catalan, and 1516 cross-linguistically. In this regard, we hope that our work will encourage the 1517 experimental exploration of the interesting variable emergence of DN readings in the 1518 cross-linguistic landscape of NC constructions.

\section{$1520 \quad$ References}

1521 Acquaviva, P. 1995. Operator composition and the derivation of Negative Concord. 1522 Geneva Generative Papers 3(2): 72-104.

1523 Acquaviva, P. 1997. The Logical Form of Negation: A Study of Operator-Variable 1524 Structures in Syntax. New York: Garland. 
1525 Badia i Margarit, A. M. 1962. Gramática catalana. Madrid: Gredos.

1526 Badia i Margarit, A. M. 1994. Gramàtica de la llengua catalana. Barcelona: 1527 Enciclopèdia Catalana.

1528 Bates, D., Maechler, M., Bolker, B. and Walker, S. 2014a. lme4: Linear mixed-effects 1529 models using Eigen and S4. R package version 1.1-7, <URL:http://CRAN.R$1530 \quad$ project.org/package=lme4>.

1531 Bates, D., Maechler, M., Bolker, B.M. and Walker, S. 2014b. Ime4: Linear mixed-effects 1532 models using Eigen and S4. ArXiv e-print; submitted to Journal of Statistical 1533 Software, <URL: http://arxiv.org/abs/1406.5823>.

1534 Benthem, J. van. 1989. Polyadic quantifiers. Linguistics and Philosophy 12, 437-464.

1535 den Besten, Hans. 1986. Double negation and the genesis of Afrikaans. In P. Muysken 1536 and N. Smith (eds.), Substrata versus Universals in Creole Languages. Papers from 1537 the Amsterdam Creole Workshop. Amsterdam: John Benjamins, 185-230.

1538 Biberauer, T. 2008. Doubling and omission: insights from Afrikaans negation. In S. 1539 Barbiers, M. van der Ham, O. Koeneman and M. Lekakou (eds.), Microvariations in $1540 \quad$ Syntactic Doubling. Bingley: Emerald, 103-140.

1541 Biberauer, T. 2009. Jespersen off course? The case of contemporary Afrikaans negation. 1542 In E. van Gelderen (ed.), Cyclical Change. Amsterdam: John Benjamins, 91-130.

1543 Biberauer, T. 2012. Competing reinforcements: when languages opt out of Jespersen's 1544 Cycle. In A. van Kemenade and N. de Haas (eds.). Historical Linguistics 2009: 1545 Selected papers from the $19^{\text {th }}$ International Conference on Historical Linguistics. 1546 Amsterdam: John Benjamins, 3-30. 
1547 Biberauer, T. 2013. The case for emergent parameters: empirical and conceptual 1548 arguments. Invited talk presented as part of the University of Kent Leverhulme 1549 Seminar Series (Canterbury, 29 July).

1550 Biberauer, T. and H. Zeijlstra. 2012. Negative Concord in Afrikaans: filling a typological 1551 gap. Journal of Semantics 29, 345-371.

1552 Bickerton, D. 1983. Creole Languages. Scientific American 249(1), 116-122.

1553 Bosque, I. 1980. Sobre la Negación. Madrid: Cátedra.

1554 Burnett, H. and M. Tremblay. 2014. L’expression de la négation en français québécois:

1555 pantoute, polarité négative et mots-n. In W. Remysen et al. (eds.), Les français d'ici.

1556 Presses universitaires de Laval, Québec, 261-290.

1557 Chierchia, G. 2006. Broaden your views: Implicatures of domain widening and the 1558 "logicality" of language. Linguistic Inquiry, 37(4), 535-590.

1559 Chomsky, N. 1995. The Minimalist Program. Cambridge, MA: the MIT Press.

1560 Chomsky, N. 2000. Minimalist Inquiries: the Framework. In R. Martin, D. Michaels and 1561 J. Uriagereka (eds.), Step by Step: Essays on Minimalist Syntax in Honor of Howard 1562 Lasnik. Cambridge, MA: the MIT Press, 89-155.

1563 Corblin, F. 1995. Compositionality and complexity in multiple negation. Logic Journal of 1564 the IGPL 3: 449-471.

1565 Corblin, F. 1996. Multiple negation processing in natural languages, Theoria, 17: 2141566259.

1567 Corblin, F. and L. Tovena. 2003. L'expression de la négation dans les langues romanes. 1568 In D. Godard (ed.), Les Langues Romances. Problèmes de la Phrase Simple. Paris: $1569 \quad$ CNRS, 281-343. 
1570 Corblin, F., Ferrando, S. and L. Kupferman. 2006. Indéfini et prédication. Paris: Presses $1571 \quad$ Universitaires de Paris-Sorbonne.

1572 Daoust-Blais, D. 1975. L'Influence de la Négation sur Certains Indéfinis en Français 1573 Québécois. PhD Thesis. Montréal, Université de Montréal.

1574 Delfitto, D. 2013. Negation as a low scope-marker in German bevor-clauses. Lingue e $1575 \quad$ Linguaggio XII(1), 73-88.

1576 Delfitto, D. and G. Fiorin. 2014. Negation in exclamatives. Studia Lingüística, 68(3), $1577 \quad 284-327$.

1578 Déprez, V. 1997a. A non-Unified Analysis of Negative Concord. In P. Hirschbühler and 1579 F. Martineau (eds.), The Syntax and Semantics of Negation. Amsterdam: John 1580 Benjamins, 53-74.

1581 Déprez, V. 1997b. Two types of Negative Concord. Probus 9(2), 103-143.

1582 Déprez, V. 1998. Semantic effects of agreement: The case of French past participle 1583 agreement. Probus, 10(1): 1-66.

1584 Déprez, V. 1999. The Roots of Negative Concord in French and French-based Creoles. In 1585 M. DeGraff (ed.), Language Creation and Language Change: Creole, Diachrony 1586 and Development. Cambridge, MA: MIT Press, 375-428.

1587 Déprez, V. 2000. Parallel (A)symmetries and the Internal Structure of Negative 1588 Expressions. Natural Language and Linguistic Theory 18(2), 253-342.

1589 Déprez, V. 2007. On the structuring role of grammaticalized morpho-syntactic features. 1590 In E. Elfner and M. Walkow (eds), Proceeding of NELS 37. Booksurge LIc 1591 Proceedings, 31-45. 
1592 Déprez, V. 2011a. From N to negative D: charting the time course of the historical rise of 1593 French NCIs. In P. Sleeman and H. Perridon (eds.), The Noun Phrase in Romance 1594 and Germanic: Structure Variation and Change. Amsterdam and Philadelphia: John $1595 \quad$ Benjamins, 257-280.

1596 Déprez, V. 2011b. Atoms of negation: An outside-in micro-parametric approach to 1597 negative concord. In P. Larrivée and R. Ingham (eds.), The Evolution of Negation: 1598 Beyond the Jespersen Cycle. Amsterdam: John Benjamins, 221-272.

1599 Déprez, V. 2014. NC vs. DN: a macroparametric variation? What can an experimental 1600 investigation tell us? Paper presented at the Linguistic Symposium of Romance 1601 Languages 44, London, University of Western Ontario.

1602 Déprez, V. (to appear) What is 'negative' in Haitian Creole ? In V. Déprez and F. Henri 1603 (eds.), Negation and Negative Concord: The view from Creoles, Amsterdam: John 1604 Benjamins.

1605 Déprez, V. and F. Martineau. 2004. Micro-Parametric Variation and Negative Concord. 1606 In J. Auger, J. Clancy Clements and B. Vance (eds.), Contemporary Approaches to 1607 Romance Linguistics. Current Issues in Linguistic Theory 258. Amsterdam and 1608 Philadelphia: John Benjamins, 139-158.

1609 Deutsch, R., R. Kordts-Freudinger, B. Gawronski, F. Strack. 2009. Fast and fragile: A 1610 new look at the automaticity of negation processing. Experimental Psychology 56(6), 1611 434-446.

1612 Di Sciullo, A.M. and M. Tremblay. 1996. Configurations et interprétation: les 1613 morphèmes de négation. Recherches Linguistiques de Vincennes 25, 27-52. 
1614 Dryer, M. S. 1996. Focus, pragmatic presupposition, and activated propositions. Journal 1615 of Pragmatics 26, 475-523.

1616 Dryer, M.S. and M. Haspelmath (eds.). 2013. World Atlas of Language Structures 1617 (WALS). Leipzig: Max Planck Institute for Evolutionary Anthropology.

1618 Espinal, M. T. 1991. On expletive negation. Some remarks with regard to Catalan. 1619 Lingvisticae Investigationes, XV(1), 41-65.

1620 Espinal, M. T. 1992. Expletive negation and logical absorption. The Linguistic Review, $16219(4), 338-358$.

1622 Espinal, M. T. 2000a. On the semantic status of NCIs in Catalan and Spanish. Lingua, $1623 \quad 110,557-580$.

1624 Espinal, M. T. 2000b. Expletive negation, negative concord and feature checking. 1625 Catalan Working Papers in Linguistics, 8, 47-69.

1626 Espinal, M. T. 2002. La negació. Gramàtica del Català Contemporani, ed. by J. Solà, 1627 M.R. Lloret, J. Mascaró, and M. Pérez-Saldanya. Chapter 24, 2687-2757. Barcelona: 1628 Empúries / Grup 62.

1629 Espinal, M. T. 2007. Licensing expletive negation and negative concord in Catalan and 1630 Spanish. In F. Floricic (ed.), La Négation Dans les Langues Romanes. Linguisticae 1631 Investigationes Supplementa 26. Amsterdam: John Benjamins, 49-74.

1632 Espinal, M. T. and P. Prieto. 2011. Intonational encoding of double negation in Catalan. $1633 \quad$ Journal of Pragmatics, 43, 2392-2410.

1634 Espinal, M. T. and S. Tubau. 2014. Interpreting argumental NCIs as answers to negative 1635 questions. Ms. Universitat Autònoma de Barcelona. Submitted. 
1636 Espinal, M. T. and S. Tubau. To appear. Meaning of words, meaning of sentences.

1637 Building the meaning of NCIs. In S. Fischer and C. Gabriel (eds.), Grammatical 1638 Interfaces in Romance Linguistics. Berlin: Mouton de Gruyter.

1639 Espinal, M. T., Tubau, S., Borràs-Comes, J. and P. Prieto. In press. Double Negation in 1640 Catalan and Spanish. Interaction between Syntax and Prosody. In P. Larrivée and C. 1641 Lee (eds.), Negation and Polarity: Cognitive and Experimental Perspectives. Berlin: 1642 Springer.

1643 Fabra, P. 1912. Gramática de la lengua catalana. Barcelona: Aqua, 1982.

1644 Fabra, P. 1918. Gramàtica catalana. Barcelona: Institut d'Estudis Catalans.

1645 Fabra, P. 1956. Gramàtica catalana. Barcelona: Teide.

1646 Falaus, A.M. 2007. Le paradoxe de la double négation dans une langue à concordance 1647 négative stricte. In F. Floricic (ed.), La Négation Dans les Langues Romanes. 1648 Amsterdam: John Benjamins, 75-97.

1649 Geurts, B. 1998. The mechanisms of denial. Language 74(2), 274-307.

1650 Giannakidou, A. 1998. Polarity Sensitivity as (Non)Veridical Dependency. Amsterdam $1651 \quad$ and Philadelphia: John Benjamins.

1652 Giannakidou, A. 2000. Negative...concord?. Natural Language and Linguistic Theory $1653 \quad 18,457-523$.

1654 Godard, D. and J. M. Marandin. 2007. Aspects pragmatiques de la négation renforcée en 1655 italien. In F. Floricic (ed.), La Négation Dans les Langues Romanes. Amsterdam: 1656 John Benjamins, 137-160.

1657 Haegeman, L. and R. Zanuttini. 1991. Negative Heads and the Neg-Criterion. The 1658 Linguistic Review 8, 233-251. 
1659 Hendriks, P., de Hoop, H., Kramer, I., de Swart, H. and J. Zwarts. 2010. Conflicts in $1660 \quad$ Interpretation. Sheffield: Equinox.

1661 Herburger, E. 2001. The Negative Concord puzzle revisited. Natural Language 1662 Semantics 9, 289-333.

1663 Horn, L. R. 1989. A Natural History of Negation. Chicago: University of Chicago Press.

1664 Hothorn, T., Bretz, F., and Westfall, P. 2008. Simultaneous Inference in General 1665 Parametric Models. Biometrical Journal 50(3), 346-363.

1666 Huddlestone, K. M. 2010. Negative Indefinites in Afrikaans. PhD Dissertation, Utrecht 1667 University.

1668 Iordăchioaia, G. 2010. Negative Concord with Negative Quantifiers: A Polyadic 1669 Quantifier Approach to Romanian Negative Concord. PhD Thesis. University of 1670 Tuebingen.

1671 Jespersen, O. 1917. Negation in English and Other Languages. Copenhaguen: A. F. Høst. 1672 Reprinted in: Selected writings of Otto Jespersen. London: George Allen \& Unwin. $1673 \quad 1962.3-151$.

1674 Kayne, R. 2005. Movement and Silence. Oxford: Oxford University Press.

1675 Keenan, E. and D. Westerståhl. 1997. Generalized quantifiers in linguistics and logic. In

1676 J. van Benthem and A. ter Meulen (eds.), Handbook of Logic and Language. 1677 Amsterdam: Elsevier, 837-893.

1678 Koopman, H. and D. Sportiche. 1991. The position of subjects. Lingua 85(2/3), 211-258.

1679 Krifka, M. 2010. How to interprete "expletive" negation under bevor in German. In T. 1680 Hanneforth and G. Fanselow (eds.), Language and Logos. Studies in Theoretical and 
1682 72).

1683 Labelle, M. and M.T. Espinal. 2014. Diachronic changes in negative expressions: the $1684 \quad$ case of French. Lingua 145, 194-225.

1685 Ladusaw, W. 1992. Expressing Negation. In C. Barker and D. Dowty (eds.), Proceedings 1686 of SALT II:237-259. Columbus: The Ohio State.

1687 Ladusaw, W. 1994. Thetic and categorical, stage and individual, weak and strong. In M.

1688 Harvey and L. Santelmann (eds.), Proceedings of SALT IV. Cornell University 1689 DMLL, 220-229.

1690 Lahiri, U. 1998. Focus and negative polarity in Hindi. Natural Language Semantics, 6, $1691 \quad 57-123$.

1692 Laka, I. 1990. Negation in Syntax: On the Nature of Functional Categories and 1693 Projections. Ph.D. Dissertation, MIT, Cambridge, Massachusetts.

1694 Linebarger, M. C. 1987. Negative polarity and grammatical representation. Linguistics 1695 and Philosophy, 10(3), 325-327.

1696 Longobardi, G. 1987. Negation parameters in Romance languages and dialects. Paper 1697 presented at the GLOW Colloquium. Venice.

1698 Makri, M-M. 2013. Expletive Negation beyond Romance. Clausal Complementation and 1699 Epistemic Modality. MA thesis. University of York.

1700 Martí i Girbau, N. 1999. Towards a unitary analysis of partitive and quantitative 1701 Constructions. Oxford University Working Papers in Linguistics, Philology \& 1702 Phonetics, 4, 84-101. 
1703 Martin, R. 1984. Pour une approche sémantico-logique du ne dit 'expletif'. Revue de $1704 \quad$ Linguistique Romane, 48, 99-120.

1705 Martins, A. M. 2000. Polarity Items in Romance: Underspecification and Lexical

1706 Change. In S. Pintzuk, G. Tsoulas and A. Warner (eds.), Diachronic Syntax: Models

1707 and Mechanisms, Oxford and New York: Oxford University Press, 191- 219.

1708 May, R. 1990. A note on quantifier absorption. The Linguistic Review 7, 121-127.

1709 Molnár, V. 1998. Topic in focus. On the syntax, phonology, semantics and pragmatics of

1710 the so-called 'contrastive topic' in Hungarian and German. Acta Linguistica $1711 \quad$ Hungarica, 45(1-2), 89-166.

1712 Muller, Claude. 1991. La négation en français. Syntaxe, sémantique et éléments de 1713 comparaison avec les autres langues romanes. Genève: Librairie Droz.

1714 Pană Dindelegan, G. (ed.). 2013. The Grammar of Romanian. Oxford: Oxford University $1715 \quad$ Press.

1716 Penka, D. 2007. Negative indefinites. Ph.D. Dissertation, University of Tuebingen.

1717 Penka, D. 2011. Negative indefinites. Oxford: Oxford University Press.

1718 Prieto, P., J. Borràs-Comes, S. Tubau and M.T. Espinal. 2013. Prosody and gesture 1719 constrain the interpretation of double negation". Lingua, 131, 136-150.

1720 Prince, E. 1992. The ZPG Letter. In W. C. Mann and S. A. Thompson (eds.), Discourse 1721 Description: Diverse Linguistic Analyses of a Fund-raising Text. Amsterdam and 1722 Philadelphia: John Benjamins, 295-325.

1723 Progovac, L. 1994. Positive and Negative Polarity: A Binding Approach. Cambridge:

1724 Cambridge University Press. 
1725 Puskás, G. 2006. Double negation and information structure: somewhere between Topic

1726 and Focus. In V. Molnár and S. Winkler (eds.), The Architecture of Focus. Berlin:

$1727 \quad$ Mouton de Gruyter, 291-317.

1728 Puskás, G. 2012. Licensing double negation in NC and non-NC languages. Natural 1729 Language and Linguistic Theory, 30, 611-649.

1730 Quer, J. 1993. The syntactic licensing of negative items. Master Thesis. Bellaterra: $1731 \quad$ Universitat Autònoma de Barcelona.

1732 Rizzi, L. 1997. The fine structure of the left periphery. In L. Haegeman (ed.), Elements of 1733 Grammar. Dordrecht: Kluwer, 281-337.

1734 Rooryck, J. 1994. On two types of underspecification: Towards a theory shared by syntax 1735 and phonology. Probus, 6, 207-233.

1736 Sleeman, P. and E.P. Kester. 2002. Partitive constructions and antisymmetry. In C.

1737 Beyssade, R. Bok-Bennema, F. Drijkoningen and P. Monachesi (eds.), Romance 1738 Languages and Linguistic Theory. Amsterdam: John Benjamins, 271-286.

1739 Solà, J. 1973. La negació. Estudis de Sintaxi Catalana, vol. 2. Barcelona: Edicions 62, $1740 \quad 87-118$.

1741 Suñer, M. 1995. Negative elements, island effects and resumptive no. The Linguistic 1742 Review, 12, 233-273.

1743 de Swart, H. 2010. Expression and Interpretation of Negation: An OT 1744 Typology. Dordrecht: Springer.

1745 de Swart, H. and I. A. Sag 2002. Negation and negative concord in Romance. Linguistics $1746 \quad$ and Philosophy 25, 373-417. 
1747 Ticio, M.E. 2005. NP-ellipsis in Spanish. In D. Eddington (ed.), Selected proceedings of 1748 the $7^{\text {th }}$ Hispanic Linguistics Symposium. Somerville Mass. Cascadilla proceedings 1749 project, 128-141.

1750 Tubau, S. 2008. Negative Concord and Romance: Syntax-morphology interface 1751 conditions on the expression of negation. $\mathrm{PhD}$ Thesis. Bellaterra: Universitat 1752 Autònoma de Barcelona and Amsterdam: University of Amsterdam.

1753 Tubau, S. and M. T. Espinal. 2012. Doble negació dins l'oració simple en català. Estudis 1754 Romànics XXXIV, 145-164.

1755 Tukey, John W. 1953. The Problem of Multiple Comparisons. Unpublished manuscript, 1756 Princeton University.

1757 Vallduví, E. 1994. Polarity items, NCIs and minimizers in Catalan and Spanish. Probus $1758 \quad 6,263-294$.

1759 Vendryes, J. 1950. Sur la négation abusive. Bulletin de la Société de Linguistique de $1760 \quad$ Paris 46(1), 1-18.

1761 Vinet, M.T. 1998. Contrastive focus, French NCIs and variation. Canadian Journal of $1762 \quad$ Linguistics, 43(1), 140-141.

1763 van der Wouden, T. 1994a. Negative contexts, $\mathrm{PhD}$ thesis. University of Groningen; 1764 published by Routledge, 1997.

1765 van der Wouden, T. 1994b. Polarity and 'illogical negation'. In M. Kanazawa and C. J. 1766 Piñón (eds.), Dynamics, Polarity and Quantification. Stanford: CSLI Publications, $1767 \quad 17-45$.

1768 van der Wouden, T. and F. Zwarts. 1993. A semantic analysis of Negative Concord. In U. 1769 Lahiri and A. Wyner (eds.), SALT III : 202-219. Ithaca NY : Cornell University. 
1770 Watanabe, A. 2004. The genesis of negative concord: syntax and morphology of negative 1771 doubling. Linguistic Inquiry 35, 559-612.

1772 Zanuttini, R. 1991. Syntactic Properties of Sentential Negation: A Comparative Study of 1773 Romance Languages. Ph.D. dissertation. University of Pennsylvania.

1774 Zanuttini, R. 1997. Negation and Clausal Structure: A Comparative Study of Romance 1775 Languages, Oxford: Oxford University Press.

1776 Zeijlstra, H. 2004. Sentential Negation and Negative Concord. PhD Thesis. University of 1777 Amsterdam.

1778 Zeijlstra, H. 2008. Negative concord is syntactic agreement. Ms. University of $1779 \quad$ Amsterdam.

1780 Zwarts, F. 1995. Nonveridical contexts. Linguistic Analysis 25, 286-312. 